\title{
Ellipticity, PDI and FLU, Evaluation of Aromaticity Indexes During Substituting B \&N Atoms in Poly-
} Annullene

\author{
Majid Monajjemi 1, *(D), Fatemeh Mollaamin 1 (D) \\ 1 Department of Chemical Engineering, Central Tehran Branch, Islamic Azad University, Tehran, Iran \\ * Correspondence: maj.monajjemi@iauctb.ac.ir;
}

Scopus Author ID 6701810683

Received: 17.06.2020; Revised: 19.07.2020; Accepted: 20.07.2020; Published: 22.07.2020

\begin{abstract}
A close relationship between chemical shift and magnetic criteria for aromaticity arouses a deeper view for probing and modeling of induced current density in $\pi$ systems through external magnetic fields. The $(4 n+2) \pi$ systems aromatic are studied on variants of Azabora Derivatives of [8] Annulene $\left(\mathrm{B}_{\mathrm{n}} \mathrm{N}_{\mathrm{n}} \mathrm{C}_{(8-2 \mathrm{n})} \mathrm{H}_{8}\right)$ via the localized orbital localization (LOL) and electron localized function (ELF) by considering the density functional calculation. By this work, it has been predicted a fourelectron dia-tropic (aromatic) ring current for $(4 n+2) \pi$ variants of $\mathrm{B}_{n} \mathrm{~N}_{n} \mathrm{C}_{(8-2 n)} \mathrm{H}_{8}$ and a two-electron para-tropic (anti-aromatic) current for (4n) $\pi$. With the HOMO and LUMO energies and also HOMO/LUMO overlapping in whole space, it is possible to predict the transition states from delocalized to-localized currents in all variant mentioned compounds in the viewpoint of aromaticity and anti-aromaticity. In addition, the nucleus independent chemical shifts (NICS), HOMA, Ellipticity, Aromatic Fluctuation index (FLU), and para delocalization index (PDI) values confirm the amounts of aromaticity and anti-aromaticity in those rings.
\end{abstract}

Keywords: Aromaticity; LOL and ELF; current density induced; paratropic and diatropic article.

(c) 2020 by the authors. This article is an open-access article distributed under the terms and conditions of the Creative Commons Attribution (CC BY) license (https://creativecommons.org/licenses/by/4.0/).

\section{Introduction}

Ellipticity $(\epsilon)$ denotes a cylindricity of the charge distribution measuring, which can be calculated through eigenvalues of the eigenvectors of the electron density. Ellipticity is described as equation (7), $\epsilon=\frac{\lambda_{1}}{\lambda_{2}}-1(\mathbf{1})$, where $\lambda_{1}$ and $\lambda_{2}$ are the negative eigenvalues of the Hessian matrix of the electron densities and $\lambda_{1}<\lambda_{2}<0$. The amounts of ellipticity with $(\epsilon)$ $>0$ generally indicate a partial $\pi$-character in a bond and a strong tool for discussing the delocalization of one-electron density along the bond path $[1,2]$.

Although the ellipticity is made by the topological situation of the electron density, which is a non- physical observable, it is an unequivocal tool for characterizing the nature of electro-cyclic induced currents. Aromatic cyclic compounds have strong correlations between bond length, electron density, the Laplacian of the electron density, the bond ellipticity, the delocalization index (DI), and the aromatic fluctuation index (FLU). Although some properties derived from the one-electron density due to the lower computational cost are important, more accurate results might be calculated from the pair density of the electron delocalization. Therefore, the application of the delocalization index derived from the bi-electronic densities for the analyzing molecular structure, chemical reactivity, and relevant works of a new local 
aromaticity criterion based on para delocalization index (PDI) is much more important $[3,4]$. PDI is a larger electronic delocalization among para-related carbons instead of meta-related in benzene, which for the first time, was exhibited by Bader and coworkers in 1996 [5]. Bader [6] illustrated regions of large electron localization having a wide value of Fermi-hole. PDI, which supplies a local criterion of aromaticity, was theoretician as the concept of all delocalization indexes of para related atoms in an aromatic ring. Parallel to NICS and HOMA, PDI is also a strong tool for estimating the aromaticity for the whole molecule and up to now has been applied for several compounds such as fullerenes [7] and nanotubes. In an approach, Becke and coworkers [8] illustrated that spherically average like-spin pair has a suitable correlation with the Fermi hole. Consequently, they introduced a new function as "electrons localization functions" (ELF). ELF(r) $=\frac{1}{1+\left[D(r) / D_{0(r)}\right]^{2}}$ (2) where $\mathrm{D}(\mathrm{r})=\frac{1}{2} \sum_{i} \eta_{i}\left|\nabla \varphi_{i}\right|^{2}-\frac{1}{8}\left[\frac{\left.|| \nabla \rho_{\alpha}\right|^{2}}{\rho_{\alpha}(r)}+\right.$ $\left.\frac{\left.|| \nabla \rho_{\beta}\right|^{2}}{\beta(r)}\right]$ (3) and $D_{0(r)}=\frac{3}{10}\left(6 \pi^{2}\right)^{\frac{2}{3}}\left[\rho_{\alpha}(r)^{\frac{5}{3}}+\rho_{\beta}(r)^{\frac{5}{3}}\right]$ (4) for closed-shell systems, since $\rho_{\alpha}(r)=\rho_{\beta}(r)=\frac{1}{2} \rho, D$ and $D_{0}$ terms can be simplified as $\mathrm{D}(\mathrm{r})=\frac{1}{2} \sum_{i} \eta_{i}\left|\nabla \varphi_{i}\right|^{2}-$ $\frac{1}{8}\left[\frac{|\nabla \rho|^{2}}{\rho(r)}\right](\mathbf{5})$ and $D_{0(r)}=\frac{3}{10}\left(3 \pi^{2}\right)^{\frac{2}{3}} \rho(r)^{\frac{5}{3}}(\mathbf{6})$. Savin et al. [9] indicated $D(\mathbf{r})$ that determines the excess kinetic energies due to the Pauli repulsion, while $D_{0}(\mathbf{r})$ is known as Thomas-Fermi kinetic energies term. In other words, they reconsidered the ELF in the viewpoint of kinetic energy through Kohn-Sham DFT's wave-function. Therefore, ELF would be in the range of $[0,1]$, and a large ELF value indicates that electrons are strongly localized. ELF is used for the wide varieties of molecules such as organic, inorganic, atomic crystals, coordination compounds, clusters, and also for aromatic rings. Localized orbital locator (LOL) is the other function similar to ELF that has been investigated by Becke and coworkers [10]. $L O L(r)=$ $\frac{\tau(r)}{1+\tau(r)}$, where $(r)=\frac{D_{0}(r)}{\frac{1}{2} \sum_{i} \eta_{i}\left|\nabla \varphi_{i}\right|^{2}}$, (7) $D_{0}(r)$ for both spin-polarized and closed-shell systems are explained in the same meaning as ELF. Jacobsen exhibited that LOL supplies a more definitive and obvious image than ELF; therefore, LOL can be interpreted in kinetic energies way better than ELF; as regards, LOL can also be interpreted in the viewpoint of localized orbital. The value ranges of LOL are similar to ELF between zero and one $[0,1]$. Since the Ellipticity, PDI, ELF and also quadrupole moment are main components in the fine structure of aromatic rings, the Azabora Derivatives of [8]-Annulene $\left({ }^{10} \mathrm{~B}_{\mathrm{n}}{ }^{14} \mathrm{~N}_{\mathrm{n}} \mathrm{C}_{(8-2 \mathrm{n})} \mathrm{H}_{8}\right)$ have been selected as a subject of this study due to the ${ }^{14} \mathrm{~N}$ atom (which is known atom in NQR spectroscopy). It is notable; boron nuclear isotopes, ${ }^{10} \mathrm{~B}$, and ${ }^{11} \mathrm{~B}$ have magnetic moments and electrical quadrupole moments. In addition, we are looking to understand in which aromaticity properties are like digit numbers (zero or one ), or this behavior is a linear combination of diatopic ring current (aromatic) in planar structure and para-tropic current (anti-aromatic) of non-planar structure. Annulene belongs to a series of conjugated monocyclic hydrocarbons with common formula $\mathrm{C}_{n} \mathrm{H}_{n}$ ( $n=$ even) or $\mathrm{C}_{n} \mathrm{H}_{n+1}$ ( $n=$ odd) such as benzene ([6]-Annulene), cyclobutadiene ([4] Annulene), cyclooctatetraene ([8]-Annulene) and cyclotetradecaheptaene ([14]-Annulene). Annulenes may be non-aromatic ([10]-Annulene), or anti-aromatic ([12]Annulene) or aromatic ([6]-Annulene). Cyclooctatetraene (COT) or [8]-Annulene, which is a poster child for non-aromatic molecules, was first synthesized by Richard Willstatter [11]. Coupling between $\mathrm{COT}^{2-}$ (or $\mathrm{B}_{4} \mathrm{~N}_{4} \mathrm{H}_{8}{ }^{2-}$ ) charges states and their mechanical conformations construct a new position for $\mathrm{COT}^{2-}$ as an aromatic molecule, including electro-mechanical converter treatment. Planar conjugated $\mathrm{COT}^{2-}$ exhibits a powerful link among $\pi$-electrons in its molecular structure. Although COT that follows a non-planar conformation with alternating 
double and single bonds via $\mathrm{D}_{2} \mathrm{~d}$ symmetry is not an aromatic molecule, $\mathrm{C}_{8} \mathrm{H}_{8}{ }^{2-}$ di- anion "cyclo-Octa- tetra-enide" is an aromatic ion with suitable resonance energy. This di-anion is planar and octagonal in its structure and aromatic with the Huckel electron count of 10. Through the interaction between alternating bonds, it has been confirmed that the structures of COT undergo a thermal shift bonding and ring inversion operations, including a planar transition state of $D_{4 h}$ [12-17]. In addition, the NMR data indicates that COT's di-anion (COT ${ }^{2-}$ ) adopts a $D_{8 h}$ symmetry structure. Although the planar $D_{4 h}$ structure for the ring inversion of COT has a transition state (TS) with barrier energy around 12 kcalmole $^{-1}$ [18-20], the $D_{8 h}$ bond switching TS lays a few kilocalories per mole higher. Actually, COT has three fundamental structural changings, including 1- ring inversions, 2-bond shifts, and 3- valences isomerization (Scheme1) [21-23]. Studies of some ions and molecules such as $\mathrm{BNC}_{6} \mathrm{H}_{8}{ }^{(0)}, \mathrm{BNC}_{6} \mathrm{H}_{8}{ }^{(2-)}$, $\mathrm{B}_{2} \mathrm{~N}_{2} \mathrm{C}_{4} \mathrm{H}_{8}{ }^{(0)}, \mathrm{B}_{2} \mathrm{~N}_{2} \mathrm{C}_{4} \mathrm{H}_{8}{ }^{2-}, \mathrm{B}_{4} \mathrm{~N}_{4} \mathrm{H}_{8}{ }^{0}$ and $\mathrm{B}_{4} \mathrm{~N}_{4} \mathrm{H}_{8}{ }^{2-}$ help to explain the details of mentioned magnetic mechanism concerning the ring induced currents related to the aromaticity behavior (Scheme 2).

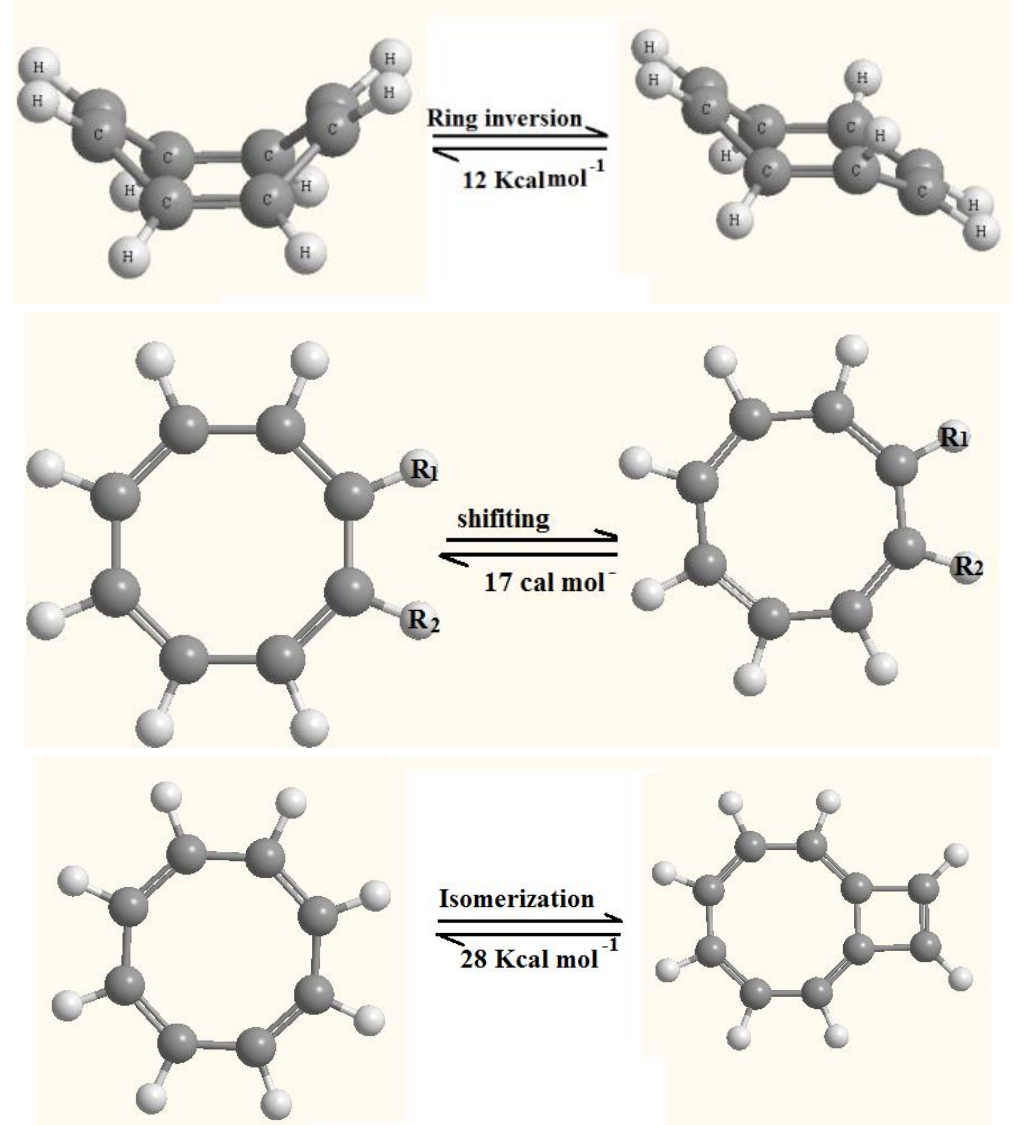

Scheme 1. Structural changes in cyclooctatetraene, including ring inversion, shifting, and valence bond isomerization.

Steiner and Fowler investigated a model via frontier-orbital contributions, which yields an accurate result of $\pi$ ring currents in benzene, $\mathrm{COT}^{2-}, \mathrm{B}_{4} \mathrm{~N}_{4} \mathrm{H}_{8}{ }^{2-}$ and such other planar rings [24, 25]. London [26], Pauling [27], and Pople [28] investigated the concept of aromaticity and anti-aromaticity in the viewpoint of magnetic criterion, diatropic (Planer of $4 n+2$ systems) and paratropic currents (planar of $4 \mathrm{n}$ systems). In recent decades, it has been exhibited that the ring current is an outcome of the HOMO-LUMO transition depends on symmetry properties and current-densities localized circulations around the electronegative nucleus [29]. For the 
systems of $\mathrm{C}_{8} \mathrm{H}_{8}{ }^{(\mathrm{n}+2)}(\mathrm{n}=-4,-2)$ \& $\mathrm{B}_{\mathrm{n}} \mathrm{N}_{\mathrm{n}} \mathrm{C}_{(8-2 \mathrm{n})} \mathrm{H}_{8}$, (n=1,2,4), densities maps exhibit the $\pi$ electrons with the localized circulations around the electronegative nucleus. It has been illustrated that the spread of the virtual orbitals is able to compute the currents in carbocyclic aromatic rings.

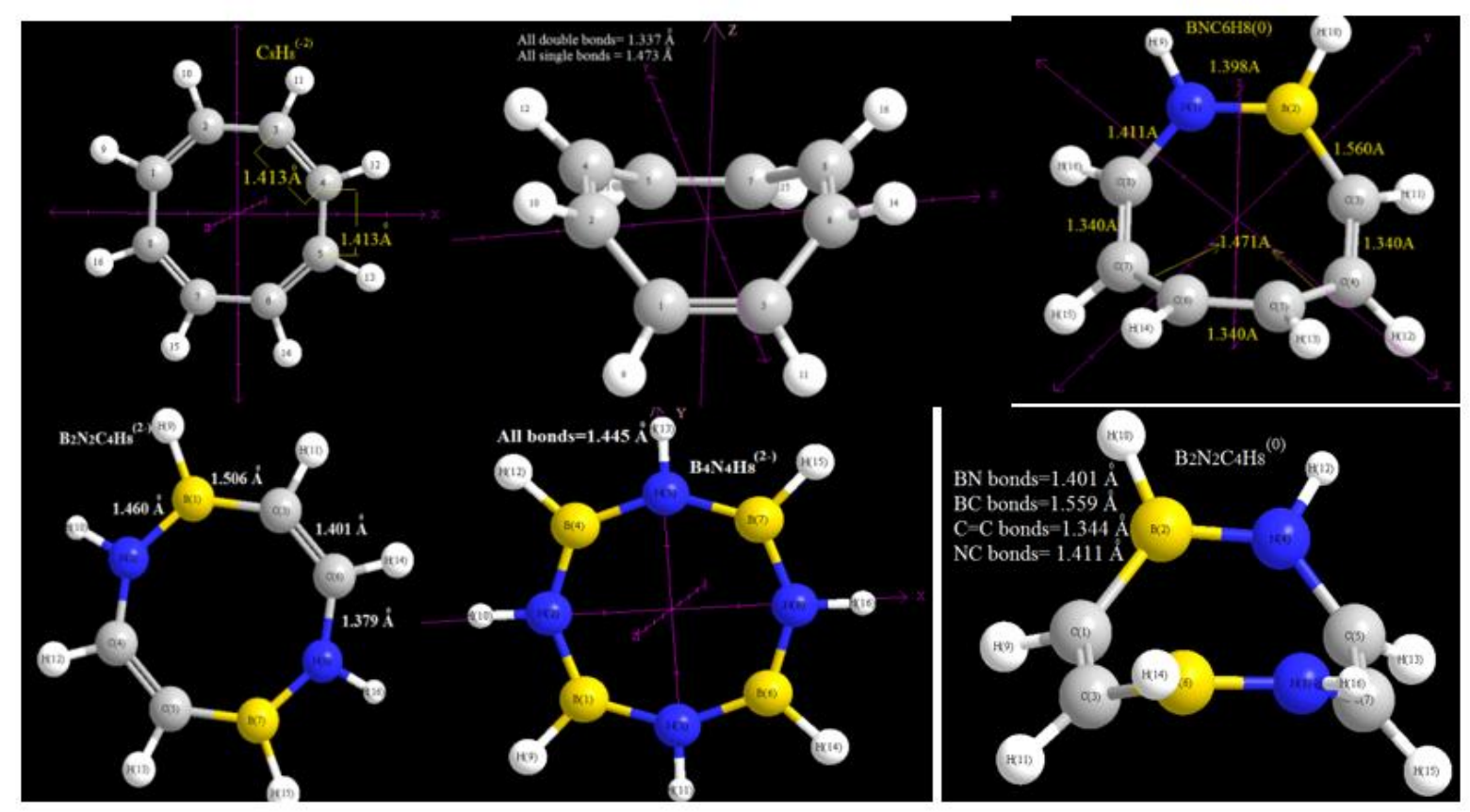

Scheme 2. Geometries optimized of variants of $\mathrm{C}_{8} \mathrm{H}_{8}{ }^{(2-)}, \mathrm{C}_{8} \mathrm{H}_{8}{ }^{(0)}$ and \& $\mathrm{B}_{n} \mathrm{~N}_{n} \mathrm{C}_{(8-2 n)} \mathrm{H}_{8},(\mathrm{n}=2,4)$.

\subsection{Induced current densities towards aromaticity.}

The theory of the induced currents densities has been investigated by Steiner via discussions of the ipsocentric approach [24, 25], which leads to a normal description of molecular orbital contributions. With supposing a closed-shell of $N$-electron systems with a pair-occupied orbitals $\psi_{\mathrm{n}}$ (which are Hartree-Fock orbitals) and $\psi_{\mathrm{p}}$ as unoccupied orbitals, in a constant magnetic field $\vec{B}$, the Hamiltonian is defined as : $\widehat{H}=\widehat{H}_{0}+\frac{e^{2}}{2 m_{e}}+\hat{I}(d) . \boldsymbol{B}$ (7) which angular momentum " $\hat{I}(d)$ " is related to momentum operator $(\hat{p}): \hat{I}(d)=(r-d) \times \hat{P}$ (8). Consequently, the induced current density" $J^{(1)}(r)$ " is a summation of two terms where for full occupied orbital $\left\{\psi_{\mathrm{n}}\right\}$ can be_written as follows: $j_{n}(r)=\frac{-e^{2}}{m_{e}} \boldsymbol{B} \times(r-d) \psi_{n}\left(r^{2}\right)+$ $\frac{2 i e \hbar}{m_{e}}\left[\psi_{n}(r) \nabla \Psi_{n}{ }^{(1)}(r)-\psi_{n}{ }^{(1)}(r) \nabla \psi_{n}(r)\right]$ (9). The first term indicates 'diamagnetic current density' $\left\{j_{n}^{\text {dia }}(r)\right\}$ which is related to the density of un-perturbed orbitals and also the second term indicates 'paramagnetic currents densities ' $\left\{j_{n}^{p r a}(r)\right\}$. Although there is no physical interpretation for this segregation of diamagnetic and paramagnetic parts, usually systems break down in two parts of diamagnetic- paramagnetic, of course, in a complete basis set. As described in reference 24 [24], the correction to each occupied orbital is a sum over occupied orbitals to unoccupied orbitals $\left\{\Psi_{p}(r)\left(P>\frac{N}{2}\right)\right\}$. Therefore, $\Psi_{n}(r)$ for one electron can be exhibited as the following equation:

$\Psi_{n}(r)=\frac{-e^{2}}{2 m_{e}}\left[\sum_{p>\frac{N}{2}} \psi_{p}(r) \frac{<\psi_{p}|\hat{I}(0)| \psi_{n}>}{\varepsilon_{p}-\varepsilon_{n}}\right] . \boldsymbol{B}+\frac{e^{2}}{2 m_{e}}\left[d \times \sum_{p>\frac{N}{2}} \psi_{p}(r) \frac{<\psi_{p}|\hat{P}| \Psi_{n}>}{\varepsilon_{p}-\varepsilon_{n}}\right] . \boldsymbol{B}$ 
First-term is $\left\{\psi_{n}^{p r a}(r)\right\}$ and $\psi_{p}|\hat{I}(0)| \psi_{n}$ is rotational transition angular momentum between energy differences of $\varepsilon_{p}-\varepsilon_{n}$ from unoccupied orbitals towards occupied orbitals. And second summation, $\left\{\psi_{p}^{\text {dia }}(r)\right\}$ and $\left\langle\psi_{p}|\hat{P}| \psi_{n}\right\rangle$ is a linear-momentum of those transition energies.

Aromaticity can be defined through magnetic criteria and is a trustworthy account of the induced currents through the external magnetic capabilities. In addition, chemical shift, isotropy, anisotropy, span, asymmetry, and other properties are all integrals of these current densities. Moreover, the currents-densities map can be estimated through theoretical methods without any gauge-dependence problem. Meanwhile, from occupied to unoccupied orbitals, the total current densities are evaluated, which are modulated and governed by energy divisors and symmetry rules, respectively. For those occupied and unoccupied orbitals without $R_{z}$, symmetry including $T_{x}$ and $T_{y}$ transition is related to the diatropic concept, while for $R_{z}$ symmetry without $\mathrm{T}_{\mathrm{x}}$ and $\mathrm{T}_{\mathrm{y}}$, these contributions have the opposite paratropic treatment [30]. For the magnetic pattern, the outcome of all such components explains the aromaticity or antiaromaticity, which is related to the net dia-tropicity and para-tropicity of the ring currents, respectively.

\subsection{Isotropic and anisotropic parameters.}

Total chemical shift tensors " $\sigma$ " are non-symmetrical tensors that can be separated through three independent parameters that are known as isotropic, traceless symmetric, and traceless anti-symmetric [31]. In addition, a spherical tensor has been exhibited by Haeberlen [32], Mehring [33], and Diehl [34]. They have investigated fundamental tensors as $\sigma=$ $\sigma^{i s o(0)}+\sigma^{\text {anti(1) }}+\sigma^{\text {sym(2) }}(\mathbf{1 1})$. Spherical tensors can also be written as $\sigma_{0}^{i s o(2)}=$ $\sqrt[2]{3 / 2} \delta_{(z z)}$ and $\sigma_{ \pm 2}^{s y m(2)}=\frac{1}{2} \delta_{(z z)}$ (12) where, $\delta_{(z z)}$ is the reduced anisotropy and can be calculated through $\left[\delta_{(z z)}=\left(\sigma_{z z}-\sigma_{i s o}\right)=\left(\sigma_{33}-\sigma_{i s o}\right)\right](\mathbf{1 3})$. This parameter is related to the anisotropy $(\Delta \sigma)$ with $\Delta \sigma=\frac{3}{2} \delta_{(z z)}(14)$. By the equations 7 and 8 , asymmetry ( $\eta$ ) shielding can be estimated as: $\Delta \sigma=\sigma_{z z}-\frac{1}{2}\left(\sigma_{x x}+\sigma_{y y}\right)$ (15) and $\eta=\left(\frac{\sigma_{y y}-\sigma_{x x}}{\delta_{(z z)}}\right)=\frac{3\left(\sigma_{y y}-\sigma_{x x}\right)}{2 \Delta \sigma}$

[35]. The magnetic resonance of the spins is seldom isotropic. Therefore, they must represent new tensors (Herzfeld-Berger notation) [36]. These tensors are known as Span $(\Omega) \Omega \geq 0$, which illustrates the maximum width of the model and the skew (к) of the tensors which are a magnitude of the values $(\Omega)=\sigma_{33}-\sigma_{11}$ and $\kappa=\frac{3\left(\sigma_{i s o}-\sigma_{22}\right)}{\Omega}$ (17). Moreover, the orientation of skew $(\kappa)$ is given by $\kappa=\frac{3\left(\sigma_{1 s o}-\sigma_{22}\right)}{\Omega}(\mathbf{1 8})(-1 \leq \kappa \leq+1)$. In some items, an axially symmetric tensor $\left(\sigma_{y y}-\sigma_{x x}\right)$ might be zero and, therefore, $\eta=0$. In addition, the asymmetry $(\eta)$ indicates how much deviation can appear from the axially symmetrical tensors, so the region of " $\eta$ " is between zero and one $(0 \leq \eta \leq+1)$.

\section{Materials and Methods}

\subsection{Computational.}

Geometry \& electronics structures have been accomplished with advanced DFT methods using m06 and cam-B3lyp series of functional. These methods are based on solution 
of Kohn-Sham orbitals [37] and Perdew exchange-correlation functional [38]. The geometry of each part of molecules and ions was optimized at the various methods, including M062x/ccpvdz, M062x/cc-pvtz, cam-B3lyp/cc-pvdz, and cam-B3lyp/cc-pvtz. Aromatic Fluctuation index (FLU), ellipticity, para delocalization index(PDI), Para linear response indexes (PLR), induced currents were calculated using the LEF, and LOL approaches with Multiwfn software [39, 40]. The contour lines of electron densities have been plotted based on Bader theory. These plots are needed for analyzing the distribution of the electrostatic potential of surfaces for each of the ions. Such contour lines have been plotted in gradient lines maps through the same items. The relief maps were applied for presenting the height data at each center. Shaded surfaces maps with and without projection are applied to represent the height values at each position. The charge transfers were also evaluated using the Merz [41], chelp, or chelpG [42, 43]. Those methods are based on our previous work[44-99] and charge fitting of electrostatic potential approaches (MESP), which are suitable for small molecules. The electron densities, values of orbitals and LUMO, HOMO orbitals, electrons spin densities, electrostatic charges, ELF, LOL, and total electrostatic potential (ESP) using the Multifunctional Wave-function analyzer have also been calculated in this work $[39,40]$. Among the several methods and basis sets that have been applied in this work, the cc-pvdz and cc-pvtz exhibit the most desirable results for ESP fitting. Isotropy and anisotropy, NICS and aromaticity data were obtained from Haeberlen [32] and Mehring [33] chemical shift tensor conventions based on Schleyer's works [15, 29]. All ab initio calculations using GAMESS-US and the optimization were done along with the frequencies calculation for confirming that the geometries have a real optimum without any imaginary frequencies.

\section{Results and Discussion}

It is now generally accepted that homologs rings of $\mathrm{C}_{8} \mathrm{H}_{8}{ }^{(0)}$ is not aromatic and, in contrast to $\mathrm{C}_{6} \mathrm{H}_{6}, \mathrm{C}_{8} \mathrm{H}_{8}{ }^{2-}$, and $\mathrm{B}_{4} \mathrm{~N}_{4} \mathrm{H}_{8}{ }^{(2-)}$ the electrons of orbital "P" are localized. By using the virtual or dummy atoms $(\mathrm{Bq})$ in the center of rings, the nucleus-independent chemical shift (NICS) has been calculated (Table 1). NICS is a simple method by Schleyer and coworkers, which estimates the absolute magnetic shielding in the center of molecules, minus NICS amount indicates aromaticity, and the positive result indicates anti-aromaticity [15, 31]. SNICS is a statistical method by a computing of nucleus independent chemical shifts in the viewpoint of probes motions in a sphere of shielding and de-shielding spaces of molecular rings [47]. The data of chemical shift tensor and other NMR components are listed in Table 1. As it can be seen, $\mathrm{C}_{8} \mathrm{H}_{8}{ }^{(0)}$ has a positive value for both NICS and S-NICS that indicates an antiaromaticity situation, while these values for other variants are negative that the sequence of aromaticity and anti-aromaticity are as:

A) anti-aromaticity: $\mathrm{B}_{4} \mathrm{~N}_{4} \mathrm{H}_{8}{ }^{(0)}>\mathrm{C}_{8} \mathrm{H}_{8}{ }^{(0)}>\mathrm{BNC}_{6} \mathrm{H}_{8}{ }^{(0)}>\mathrm{B}_{2} \mathrm{~N}_{2} \mathrm{C}_{4} \mathrm{H}_{8}{ }^{(0)}$

B): aromaticity: $\mathrm{B}_{2} \mathrm{~N}_{2} \mathrm{C}_{4} \mathrm{H}_{8}{ }^{2-}<\mathrm{B}_{4} \mathrm{~N}_{4} \mathrm{H}_{8}{ }^{2-}<$ benzene $<\mathrm{BNC}_{6} \mathrm{H}_{8}{ }^{(2-)}<\mathrm{C}_{8} \mathrm{H}_{8}{ }^{2-}$

Although the electronic delocalization is not an observable phenomenon, electronic delocalization is appeared in a few chemical reactions depending on aromatic molecules. A basic analysis of delocalization is the magnetic field of compounds such as anisotropy and isotropy of magnetic capabilities in the NMR using a probe for estimating magnetic shielding in the center of aromatic and $\pi$-conjugated rings (Table 1). 
Table 1. Herzfeld-Berger \& Haeberlen convention of NMR components with Cam-b3lyp/cc-pvdz calculation for $\mathrm{BNC}_{6} \mathrm{H}_{8}{ }^{(-2)}, \mathrm{BNC}_{6} \mathrm{H}_{8}{ }^{(0)}, \mathrm{C}_{8} \mathrm{H}_{8}{ }^{0}, \mathrm{C}_{8} \mathrm{H}_{8}{ }^{2-}, \mathrm{B}_{2} \mathrm{~N}_{2} \mathrm{C}_{4} \mathrm{H}_{8}{ }^{2-}, \mathrm{B}_{2} \mathrm{~N}_{2} \mathrm{C}_{4} \mathrm{H}_{8}{ }^{2-}, \mathrm{B}_{4} \mathrm{~N}_{4} \mathrm{H}_{8}{ }^{2-}$ and $\mathrm{B}_{4} \mathrm{~N}_{4} \mathrm{H}_{8}{ }^{(0)}$ compare to benzene.

\begin{tabular}{l|l|l|l|l|l|l|l|l|l}
$\begin{array}{l}\text { Ions } \\
\text { \&Molecules }\end{array}$ & $\boldsymbol{\sigma}_{\mathbf{1 1}}$ & $\boldsymbol{\sigma}_{\mathbf{2 2}}$ & $\boldsymbol{\sigma}_{\mathbf{3 3}}$ & $\boldsymbol{\sigma}_{\text {iso }}$ & $\begin{array}{c}\boldsymbol{\sigma}_{\text {aniso }} \\
\boldsymbol{y} \boldsymbol{\delta}\end{array}$ & $\boldsymbol{\kappa}$ & $\boldsymbol{\Omega}$ & $\boldsymbol{\eta}$ & NICS \\
\hline $\mathrm{BNC}_{6} \mathrm{H}_{8}^{(-2)}$ & 5.26 & 5.40 & 29.2 & 13.27 & 23.8 & -0.98 & 23.9 & 0.00 & -13.3 \\
\hline $\mathrm{BNC}_{6} \mathrm{H}_{8}^{(0)}$ & 5.76 & 3.28 & -18.1 & -3.00 & -22.5 & 0.79 & 23.8 & 0.16 & 3.00 \\
\hline $\mathrm{B}_{2} \mathrm{~N}_{2} \mathrm{C}_{4} \mathrm{H}_{8}{ }^{(2-)}$ & 5.52 & 4.13 & 8.9 & 6.19 & 4.1 & -0.42 & 4.8 & 0.51 & -6.2 \\
\hline $\mathrm{B}_{2} \mathrm{~N}_{2} \mathrm{C}_{4} \mathrm{H}_{8}{ }^{(0)}$ & 4.21 & 5.08 & -15.2 & -1.7 & -20.0 & 0.99 & 20.0 & 0.00 & 1.7 \\
\hline $\mathrm{C}_{6} \mathrm{H}_{6}$ & 5.55 & 6.28 & 13.9 & 8.56 & 7.9 & -0.82 & 8.30 & 0.14 & -9.6 \\
\hline $\mathrm{C}_{8} \mathrm{H}_{8}(2-)$ & 3.4 & 3.4 & 40.9 & 15.9 & 37.6 & -0.99 & 33.7 & 0.0 & -15.9 \\
\hline $\mathrm{C}_{8} \mathrm{H}_{8}^{(0)}$ & 4.8 & 4.8 & -21.2 & -3.9 & -26.0 & +0.99 & 26 & 0.0 & +3.9 \\
\hline $\mathrm{B}_{4} \mathrm{~N}_{4} \mathrm{H}_{8}^{(2-)}$ & 1.97 & 1.97 & 23.6 & 9.17 & 21.6 & -0.99 & 21.6 & 0.0 & -9.2 \\
\hline $\mathrm{B}_{4} \mathrm{~N}_{4} \mathrm{H}_{8}{ }^{(0)}$ & 4.96 & 4.98 & -22.0 & -4.19 & -27.5 & 0.99 & 27.5 & 0.0 & +4.2
\end{tabular}

In addition, bond length parity between single and double bonds in $\pi$-conjugated rings is based on electron delocalization. Therefore, the HOMO, LUMO, and overlapping between these MO orbitals can be useful to determine the regions of molecular space where electron pairs are located. In this work, not only HOMO/LUMO overlaps but also HOMO/HOMO-1 overlapping in whole spaces has been applied for the estimation of localized and non-localized electrons (Table 2).

Table 2. HOMO and LUMO overlapping.

\begin{tabular}{l|c|c|c}
$\begin{array}{l}\text { Ion \& } \\
\text { Molecule }\end{array}$ & $\begin{array}{c}\text { HOMO/ } \\
\text { LUMO } \\
\text { Gap energy }\end{array}$ & $\begin{array}{c}\text { HOMO/LUMO } \\
\text { overlap in whole space }\end{array}$ & $\begin{array}{c}\text { HOMO/HOMO-1 } \\
\text { overlap in whole space }\end{array}$ \\
\hline $\mathrm{BNC6H} 8^{(-2)}$ & $5.32 \mathrm{eV}$ & 0.327 & 0.674 \\
\hline $\mathrm{BNC6H} 8^{(0)}$ & $7.58 \mathrm{eV}$ & 0.754 & 0.846 \\
\hline $\mathrm{B} 2 \mathrm{~N} 2 \mathrm{C} 4 \mathrm{H} 8^{(0)}$ & $8.01 \mathrm{eV}$ & 0.658 & 0.723 \\
\hline $\mathrm{B} 2 \mathrm{~N} 2 \mathrm{C} 4 \mathrm{H}^{(2-)}$ & $4.055 \mathrm{eV}$ & 0.333 & 0,554 \\
\hline $\mathrm{B} 4 \mathrm{~N} 4 \mathrm{H} 8^{2-}$ & $3.54 \mathrm{eV}$ & 0.348 & 0.338 \\
\hline $\mathrm{B} 4 \mathrm{~N} 4 \mathrm{H} 8^{(0)}$ & $8.52 \mathrm{eV}$ & 0.381 & 0.718 \\
\hline $\mathrm{C} 8 \mathrm{H} 8^{(2-)}$ & $5.38 \mathrm{eV}$ & 0.377 & 0.762 \\
\hline $\mathrm{C} 8 \mathrm{H} 8^{(0)}$ & $7.26 \mathrm{eV}$ & 0.791 & 0.857
\end{tabular}

In Huckel theory for $N$ atoms with equal coulomb parameters $\{\alpha\}$ and equal resonance parameter $\{\beta\}$, the $\{\pi\}$ energies can be calculated easily by the well-known method [100].

Therefore, for the $4 n+2$ systems (with higher symmetry) only the HOMO-LUMO transitions are considered (dia-tropic current), and for the " $4 \mathrm{n}$ " ring (lower symmetry) two forms can be considered, first the HOMO-LUMO transition leads to a para-tropic contribution, and second HOMO-LUMO+1 transitions to the dia-tropic contributions [100,101]. Since in the closed-shell of the $4 n+2$ systems, the appearance of the occupied orbital in the complete shells, in-plane rotation only the orbitals with the same $\{\lambda\}$ can be overlapped together, and it cannot occur by occupied-to-virtual transitions. On the other side, the mixed adjacent orbitals must differ by $\{\Delta \lambda= \pm 1\}$. The lonely Occupied-Virtual-Translational (OVT) transition in the $(4 n+2)$ system are therefore HOMO to LUMO, and so, in this system of a mono-ring, the ring current occurs only by the HOMO orbitals which are fully diamagnetic, but in $n=0$ the HOMO with degeneracy $=2$ and the $(4 n+2)$ system has four-electron in diamagnetism situation. In $4 n$, the $\{\pi\}$ systems have half-filling of the angular momentums. Therefore in full $\boldsymbol{D}_{n h}$ symmetry, it goes towards an open-shell configuration with a distorting degeneracy. By reducing the symmetry, HOMO \&LUMO pairs split into non-degenerate orbitals relevant via a rotational transition with the small energies divisors. As can be seen in table 2, the gap energies (a), HOMO/LUMO overlap amounts (b), and HOMO/HOMO-1 overlap amounts (c) in whole 
spaces obey the sequence as follows, respectively (a,b \& c). It has been exhibited the sequences of aromaticity are a part of (b), and the sequence of anti-aromaticity is a part of (c), while induced current densities have a straight relation with gap energies [102,103].

(a): $\mathrm{B}_{4} \mathrm{~N}_{4} \mathrm{H}_{8}{ }^{2-}<\mathrm{B}_{2} \mathrm{~N}_{2} \mathrm{C}_{4} \mathrm{H}_{8}{ }^{2-}<\mathrm{C}_{8} \mathrm{H}_{8}{ }^{2-} \sim \mathrm{C}_{8} \mathrm{H}_{8}{ }^{0}<\mathrm{BNC}_{6} \mathrm{H}_{8}{ }^{(0)}<\mathrm{B}_{2} \mathrm{~N}_{2} \mathrm{C}_{4} \mathrm{H}_{8}{ }^{(0)}<\mathrm{B}_{4} \mathrm{~N}_{4} \mathrm{H}_{8}{ }^{(0)}$

(b): $\mathrm{B}_{2} \mathrm{~N}_{2} \mathrm{C}_{4} \mathrm{H}_{8}{ }^{2-}<\mathrm{B}_{4} \mathrm{~N}_{4} \mathrm{H}_{8}{ }^{2-}<\mathrm{C}_{8} \mathrm{H}_{8}{ }^{2-}<\mathrm{B}_{4} \mathrm{~N}_{4} \mathrm{H}_{8}{ }^{(0)}<\mathrm{B}_{2} \mathrm{~N}_{2} \mathrm{C}_{4} \mathrm{H}_{8}{ }^{(0)}<\mathrm{BNC}_{6} \mathrm{H}_{8}{ }^{(0)}<\mathrm{C}_{8} \mathrm{H}_{8}{ }^{0}$

(c): $\mathrm{B}_{4} \mathrm{~N}_{4} \mathrm{H}_{8}{ }^{2-}<\mathrm{B}_{2} \mathrm{~N}_{2} \mathrm{C}_{4} \mathrm{H}_{8}{ }^{2-}<\mathrm{B}_{4} \mathrm{~N}_{4} \mathrm{H}_{8}{ }^{(0)}<\mathrm{B}_{2} \mathrm{~N}_{2} \mathrm{C}_{4} \mathrm{H}_{8}{ }^{(0)}<\mathrm{C}_{8} \mathrm{H}_{8}{ }^{2-}<\mathrm{BNC}_{6} \mathrm{H}_{8}{ }^{(0)}<\mathrm{C}_{8} \mathrm{H}_{8}{ }^{0}$

which means HOMO/LUMO overlap amounts in whole spaces can be considered as an index for aromaticity while $\mathrm{HOMO} / \mathrm{HOMO}-1$ overlapping for anti-aromaticity.

These HOMO/LUMO overlapping indicate the sum over states, producing a strong two-electron paramagnetic ring current, which is a maximum for the $\mathrm{C}_{8} \mathrm{H}_{8}{ }^{(0)}$ and a minimum for $\mathrm{B}_{2} \mathrm{~N}_{2} \mathrm{C}_{4} \mathrm{H}_{8}{ }^{2-}$. Other rotational \& translational transition presented through the lower symmetry and has a minor important in small cycles. The $\mathrm{C}_{8} \mathrm{H}_{8}{ }^{2-}$ and $\mathrm{B}_{4} \mathrm{~N}_{4} \mathrm{H}_{8}{ }^{(2-)}$ are structured with $\sigma / \sigma^{*}$ orbitals around $\pi / \pi^{*}$ molecular orbitals where the overlapping of $\sigma / \pi$ separation has been missed. On the other hand, for the systems such as $\mathrm{B}_{2} \mathrm{~N}_{2} \mathrm{C}_{4} \mathrm{H}_{8}{ }^{2-}$ and $\mathrm{B}_{4} \mathrm{~N}_{4} \mathrm{H}_{8}{ }^{2-}$ with the orbitals of a hetero-cycle localize under large electronegativity will normally lead to the loss of ring current (Fig. 1).
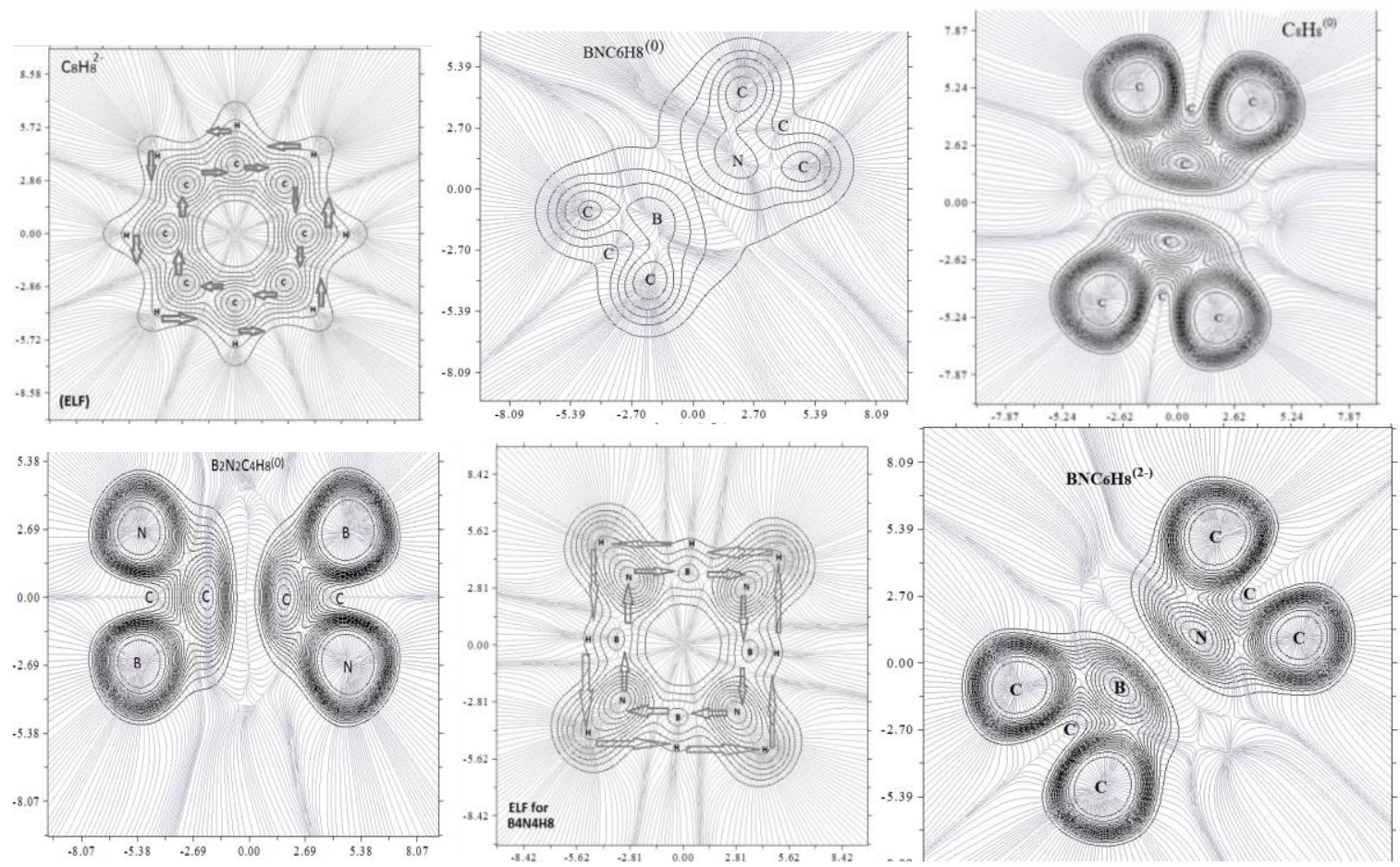

Figure 1. Gradient lines map of ELF and current density induced in cyclooctatetraene C8H82-, B4N4H82-, B2N2C4H8(0), BNC6H82-, BNC6H80 and C8H80 by a perpendicular external magnetic field calculated by the

Cam-B3lyp/cc-pvtz method. Anticlockwise circulations are Dia-tropic, clockwise circulations Para-tropic.

In Table 3, the sequences of ring perimeter and ring area $\left(\AA^{2}\right)$ are dependent on firstly the number of pi electrons and secondly the number of pi orbitals. Therefore, for $\mathrm{BNC}_{6} \mathrm{H}_{8}{ }^{2-}$, $\mathrm{B}_{2} \mathrm{~N}_{2} \mathrm{C}_{4} \mathrm{H}_{8}{ }^{2-}$ and $\mathrm{B}_{4} \mathrm{~N}_{4} \mathrm{H}_{8}{ }^{2-}$ ions, it is needed to rearrange the coulomb and resonance integral equation as: boron and nitrogen are zero and two-electron donors with orbital energies equal $(\alpha-\beta)$ and $(\alpha+1.5 \beta)$, respectively. Therefore, in the structure of these molecules with the differing electro-negativities of boron and nitrogen, a symmetric changing to the coulomb parameters yield $(\alpha-\gamma \beta)$ and $(\alpha+\gamma \beta)$ energies which $\gamma$ is a correlated parameter in various structures and varied between $0 \leq \gamma<1$. A solution of the Huckel equation via considering the $\gamma$ parameter with a simple modification gives molecular orbitals $\{\varnothing\}$ and related energies $\{\varepsilon\}$ 
from which the consequences for cycle currents can be deduced. Canonical molecular orbitals $\left(\Psi_{\lambda, c}\right)$ are delocalized set with $(\gamma=0)$, and in each position of $\gamma \neq 0$ a linear combination of these sets can be written for orbitals. In the full symmetrical systems of carbocyclic, the degeneracy of $\Psi_{2, c}$ and $\Psi_{2, s}$ can be stabilized in several ways, such as distortion to $\mathrm{D}_{2 \mathrm{~d}}$ and $\mathrm{D}_{4 \mathrm{~h}}$ geometries of COT systems [53]. Due to its bond alternation, $D_{4 h}$ COT keeps delocalized orbitals and also the cycle current of the equilateral carbocyclic (Fig. 1). In the heterocyclic systems $(\gamma \neq 0), \Psi_{2, c}$ and $\Psi_{2, s}$ are bonding and anti-bonding wave functions which belong to the $\mathrm{B}_{1 \mathrm{u}}$ and $\mathrm{B}_{2 \mathrm{u}}$ symmetric on the $\mathrm{D}_{4 h}$ subunits of $\mathrm{D}_{8 h}$ character tables. It is notable that wave functions of $\Psi_{2, c}$ and $\Psi_{2, s}$ are the HOMO and LUMO for all amounts of $\gamma$, which are completely localized; the HOMO on the nitrogen atom and the LUMO on the boron atom. Obviously, $\varnothing_{0, c}$ $, \emptyset_{1, c}, \emptyset_{1, s}, \emptyset_{3, c}, \emptyset_{3, s}$ and $\emptyset_{4, c}$, become strongly localized on the electronegative atoms. In the $\gamma=1$, the nitrogen and boron atoms obey Huckel's population as $1 \pm \frac{1}{2}\left(\frac{1}{2}+\frac{1}{\sqrt{3}}+\frac{1}{2 \sqrt{5}}\right) \approx 1.66$ and 0.36 electrons, respectively. In the Huckel-London approach, the ring current of the eightmembered ring in a small amount of $\gamma$, HOMO-LUMO contribution overcomes to the bondbond polarizability. By increasing the $\gamma$ from the planar-constrained of COT (where $\gamma=0$ ) to the $\mathrm{B}_{4} \mathrm{~N}_{4} \mathrm{H}_{8}$ planer (where $\gamma=1$ ), the eight-membered ring has still net para-tropic circulation. The symmetry conclusion deducts the line currents in $4 n \pi$ position, including several steps; firstly $(\gamma \approx 0)$, those currents are overmatched via the HOMO-LUMO transitions among small gap energies. This situation $(\Delta \lambda=0)$ generates a para-tropic intensity. In other words, the symmetry reasoning for deducing the currents in $4 \mathrm{n}$ systems consist of several levels from $(\gamma$ $=0$ ), which the current is under HOMO-LUMO transition with a small energy gap towards $\gamma$ $=1$, the HOMO-LUMO gap opens the intensities of the currents fall but remain paramagnetic. Here, the separation of HOMO-1 and LUMO, as well as HOMO and LUMO+1, increases slowly, and the para-tropic or anti-aromatic cycle current is reduced significantly (Tables $2 \& 3$ ). Investigation of symmetry can be applied for an understanding ring and perimeter currents in those systems. Rings perimeter $(\AA)$ and the area $\left(\AA^{2}\right)$ of those molecules are listed in Table 3 . Based on these data, the rings perimeter values and the area values have not a linear relation together due to the non-geometrical behavior of aromaticity in hetero molecules, including boron and nitrogen.

Table 3. Ring area $\left(\AA^{2}\right)$, Ring perimeter $(\AA)$, and No. Pi orbitals \& Pi- electrons.

\begin{tabular}{|c|c|c|c|}
\hline Molecule & $\begin{array}{c}\operatorname{Ring} \\
\operatorname{area}\left(\AA^{2}\right)\end{array}$ & $\begin{array}{c}\text { Ring perimeter } \\
(\AA)\end{array}$ & $\begin{array}{c}\text { No. Pi orbitals \& Pi- } \\
\text { electrons }\end{array}$ \\
\hline $\mathrm{BNC}_{6} \mathrm{H}_{8}{ }^{(-2)}$ & 9.81 & 11.41 & $3 \& 6$ \\
\hline $\mathrm{BNC}_{6} \mathrm{H}_{8}{ }^{(0)}$ & 9.59 & 11.32 & HOMO \& 2 \\
\hline $\mathrm{C}_{8} \mathrm{H}_{8}{ }^{(2-)}$ & 9.63 & 11.30 & $5 \& 10$ \\
\hline $\mathrm{C}_{8} \mathrm{H}_{8}{ }^{(0)}$ & 9.39 & 11.24 & HOMO \& 2 \\
\hline $\mathrm{B}_{4} \mathrm{~N}_{4} \mathrm{H}_{8}(2-)$ & 10.04 & 11.56 & $5 \& 10$ \\
\hline $\mathrm{B}_{4} \mathrm{~N}_{4} \mathrm{H}_{8}{ }^{(0)}$ & 9.79 & 11.41 & HOMO \& 2 \\
\hline $\mathrm{B}_{2} \mathrm{~N}_{2} \mathrm{C}_{4} \mathrm{H}_{8}{ }^{(2-)}$ & 9.93 & 11.48 & $5 \& 10$ \\
\hline $\mathrm{B}_{2} \mathrm{~N}_{2} \mathrm{C}_{4} \mathrm{H}_{8}{ }^{(0)}$ & 9.66 & 11.42 & HOMO \& 2 \\
\hline
\end{tabular}

In Table 4, Para linear response indexes (PLR), Para delocalization index (PDI), Aromatic fluctuation index (FLU), FLU $\pi$, and DI $\pi$ are listed. PDI is an important electronic criterion based on local aromaticity, which has been defined by Bader for larger electronic delocalization among para- carbon position (instead of Meta carbons) in benzene. PDI, which provides a local criterion of aromaticity, can be calculated as the mean of all delocalization of para- carbon atoms. In Figs. 2\&3, PDI versus HOMA and NICS have been plotted, as it can be seen a suitable correlation is attained between HOMA-PDI and NICS-PDI. The PDI of 
$\mathrm{B}_{4} \mathrm{~N}_{4} \mathrm{H}_{8}{ }^{(0)}$ with the lowest delocalization has a non-aromatic ring due to its partial $\pi$-bond localization that disfavors particularly the delocalization between $\mathrm{B}$ and $\mathrm{N}$ atoms in para positions. Although PDI for $\mathrm{C}_{8} \mathrm{H}_{8}{ }^{(0)}$ is close to other compounds, its FLU has the largest amount compared to other molecules, which causes an anti-aromaticity for these molecules. As a result, both PDI and FLU together might be a good index for separating anti-aromaticity from aromaticity in such molecules. The aromatic fluctuation index will be zero for those molecules with a complete symmetrical structure or molecules with high aromaticity or both. Therefore, the FLU for these kinds of molecules is zero. FLU also describes the fluctuation of charges among adjacent centers in a given aromatic ring. Fluctuation index fundamentally is related to the delocalized circulation of $\pi$ electrons, which is not only the amount of electron sharing among connected atoms but also the similarity of electron sharing among contiguous atoms.

Table 4. NICS, HOMA, FLU, PDI, FLU $\pi$, Di $\pi$ and PLR of molecules.

\begin{tabular}{l|c|c|c|c|c|c|c} 
Molecules & NICS & HOMA & $\begin{array}{c}\text { Aromatic } \\
\text { fluctuation } \\
\text { index (FLU) }\end{array}$ & $\begin{array}{c}\text { Para delocalization } \\
\text { index } \\
\text { (PDI) }\end{array}$ & FLU $\pi$ & DI $\pi$ & $\begin{array}{c}\text { Para linear esponse } \\
\text { indexes(PLR) }\end{array}$ \\
\hline $\mathrm{BNC}_{6} \mathrm{H}_{8}{ }^{(-2)}$ & -13.27 & 0.689 & 0.000 & 0.037 & 0.43 & 0.179 & 0.16 \\
\hline $\mathrm{BNC}_{6} \mathrm{H}_{8}(0)$ & 3.00 & 0.145 & 0.02 & 0.033 & 1.83 & 0.056 & 0.11 \\
\hline $\mathrm{C}_{8} \mathrm{H}_{8}{ }^{(2-)}$ & -15.9 & 0.591 & 0.000 & 0.031 & 0.0 & 0.443 & 0.12 \\
\hline $\mathrm{C}_{8} \mathrm{H}_{8}(0)$ & +3.9 & 0.121 & 0.052 & 0.032 & No & 0.059 & 0.08 \\
\hline $\mathrm{B}_{4} \mathrm{~N}_{4} \mathrm{H}_{8}^{(2-)}$ & -9.17 & 0.973 & 0.000 & 0.032 & 0.0 & 0.379 & 0.16 \\
\hline $\mathrm{B}_{4} \mathrm{~N}_{4} \mathrm{H}_{8}\left({ }^{(0)}\right.$ & +4.19 & 0.122 & 0.02 & 0.011 & No & 0.065 & 0.03 \\
\hline $\mathrm{B}_{2} \mathrm{~N}_{2} \mathrm{C}_{4} \mathrm{H}_{8}(2)$ & -6.19 & 0.453 & 0.000 & 0.036 & 0.01 & 0.041 & 0.36 \\
\hline $\mathrm{B}_{2} \mathrm{~N}_{2} \mathrm{C}_{4} \mathrm{H}_{8}(0)$ & 1.7 & 0.113 & 0.011 & 0.028 & 0.65 & 0.239 & 0.10
\end{tabular}

As it can be seen in table 4, FLU $\pi$ index which calculates only the $\pi$-component of the DIs at difference FLU might be matched with FLU for all aromatic rings (not for anti-aromatic compounds); thus, the use of FLU $\pi$ for planar systems is necessary for any further prediction of aromaticity in those rings. In this work, FLU has been calculated for all compounds, including aromatic or non-aromatic, to determine local or global aromaticity. In Figs 2-4, FLU has been plotted versus HOMA, NICS, and rings area, respectively, and a clear correlation appears between $\mathrm{X}$ and $\mathrm{Y}$-axis. Moreover, the Para linear response indexes (PLR) for aromatic compounds are larger than the anti-aromatic molecules. Consequently, for predication of a cyclic compound as an aromatic ring or non-aromatic ring, an individual index is not sufficient by itself. For instance, $\mathrm{B}_{4} \mathrm{~N}_{4} \mathrm{H}_{8}{ }^{(2-)}$ and $\mathrm{C}_{8} \mathrm{H}_{8}{ }^{(2-)}$ are aromatic due to all indexes including FLU $=0.0,0.01<\mathrm{PDI}<0.04$, negative NICS, $0.5<\mathrm{HOMA}<1,<0.1 \mathrm{PLR}<0.2$ and DI $\pi \sim 0.4$. It is notable benzene has a nice correspondence with the mentioned ranges for $\mathrm{B}_{4} \mathrm{~N}_{4} \mathrm{H}_{8}{ }^{(2-)}$ and $\mathrm{C}_{8} \mathrm{H}_{8}{ }^{(2-)}$; although the PDI for $\mathrm{C}_{8} \mathrm{H}_{8}{ }^{(0)}, \mathrm{B}_{4} \mathrm{~N}_{4} \mathrm{H}_{8}{ }^{(0)}$ are between $0.01<\mathrm{PDI}<0.04$, positive NICS or FLU $\neq 0$ or $\mathrm{HOMA}<0.2$ causes these compounds strongly to be anti-aromatic rings. Therefore, an individual vision of aromaticity indexes based on NICS, HOMA, FLU, FLU $\pi$, PDI, LOL and ELF variables is not sufficient, and it is necessary to consider a few of these variables for any prediction and discussion due to this reality that aromaticity is no like a digital number [ 1 or zero ]. LOL and ELF data from ab-initio calculations of $\mathrm{BNC}_{6} \mathrm{H}_{8}{ }^{(0)}, \mathrm{BNC}_{6} \mathrm{H}_{8}{ }^{(2-}$ ), $\mathrm{C}_{8} \mathrm{H}_{8}{ }^{(-2)}, \mathrm{C}_{8} \mathrm{H}_{8}{ }^{(0)}, \mathrm{B}_{N} \mathrm{C}_{4} \mathrm{H}_{8}{ }^{2-}$ and $\mathrm{B}_{4} \mathrm{~N}_{4} \mathrm{H}_{8}{ }^{2-}$ are listed in table 5 and plotted in Fig. 1. These data have been calculated based on choosing the occupied pi orbitals (no virtual pi orbitals) whose numbers are mentioned in table 5. As can be seen, the LOLIOP for those anti-aromatic molecules is zero, and for other variants depends on their structures that are larger than "2". In Figs. 2\&3, the LOLIOP has been plotted versus related HOMA and NICS values. HOMA is theoretician based on the number of optimal bonds as HOMA $=1$ for those systems with all bonds equal to an optimal value for reaching to fully aromatic systems. An acceptable 
correlation is found between HOMA and NICS values, Figs. 2\&3, due to geometry-based ones of the equation as: HOMA $=1-\frac{\alpha}{n} \sum_{i=1}^{n}\left(R_{o p t}-R_{i}\right)^{2}$ which depends on atoms of aromatic ring position. It is notable, $n$ is the number of bonds, and " $\alpha$ " is an empirical parameter for producing HOMA between zero and one for the non-aromatic systems towards a fully aromatic system.

Table 5. NICS, HOMA, and LOL, including $\pi$ energies of molecular systems.

\begin{tabular}{|c|c|c|c|c|}
\hline Molecules & $\begin{array}{c}\text { No. pi occupied orbitals and energy } \\
(\mathrm{eV})\end{array}$ & $\begin{array}{l}\text { LOL integrated pi over plan } \\
\text { (LOLIOP) }\end{array}$ & HOMA & NICS \\
\hline $\mathrm{BNC}_{6} \mathrm{H}_{8}{ }^{(-2)}$ & $\begin{array}{c}\text { No. } 27=0.889 ; \text { No2 } 2=3.98 \\
\text { No. } 29=5.16(\mathrm{HOMO})\end{array}$ & 2.54 & 0.689 & -13.27 \\
\hline $\mathrm{BNC}_{6} \mathrm{H}_{8}{ }^{(0)}$ & No.28 (HOMO)=-7.37 & 0.0 & $* * * * *$ & $* * * * *$ \\
\hline $\mathrm{C}_{8} \mathrm{H}_{8}{ }^{(2-)}$ & $\begin{array}{c}\text { No. } 23=-1.25 \text {, No. } 26=0.382, \\
\text { No. } 27=0.383 \text {, No. } 28=4.6612 \\
\text { No. } 29=4.6613 \text { (HOMO) }\end{array}$ & 3.93 & 0.591 & -15.9 \\
\hline $\mathrm{C}_{8} \mathrm{H}_{8}{ }^{(0)}$ & No. $28(\mathrm{HOMO})=-7.25$ & 0.0 & $* * * * *$ & $* * * *$ \\
\hline $\mathrm{B}_{4} \mathrm{~N}_{4} \mathrm{H}_{8}(2-)$ & $\begin{array}{c}\text { No. } 22=-1.86, \text { No. } 26=-0.5513 \text {, } \\
\text { No. } 27=-0.5514, \text { No. } 28=1.476 \\
\text { No. } 29=6.5814 \text { (HOMO) }\end{array}$ & 3.08 & 0.973 & -9.17 \\
\hline $\mathrm{B}_{4} \mathrm{~N}_{4} \mathrm{H}_{8}{ }^{(0)}$ & No.28 (HOMO) $=-8.37$ & 0.0 & $* * * * *$ & $* * * * *$ \\
\hline $\mathrm{B}_{2} \mathrm{~N}_{2} \mathrm{C}_{4} \mathrm{H}_{8}{ }^{(2-)}$ & $\begin{array}{c}\text { No. } 21=-2.026 \text {, No. } 23=-1.473 \\
\text { No. } 27=1.304, \text { No. } 28=3.152 \\
\text { No. } 29=5.706 \text { (HOMO) }\end{array}$ & 6.02 & 0.453 & -6.19 \\
\hline $\mathrm{B}_{2} \mathrm{~N}_{2} \mathrm{C}_{4} \mathrm{H}_{8}{ }^{(0)}$ & No.28 (HOMO) $=-7.65$ & 0.0 & $* * * * *$ & $* *$ \\
\hline
\end{tabular}

A symmetrical distribution of electron densities, ELF, and LOL densities including DOS, PDOS, TDOS, and OPDOS for $\mathrm{C}_{8} \mathrm{H}_{8}{ }^{(2-)}$ and $\mathrm{B}_{4} \mathrm{~N}_{4} \mathrm{H}_{8}{ }^{(2-)}$ can be seen in Figs. 5-7, which indicates an iso-structure between these two compounds and $\mathrm{C}_{8} \mathrm{H}_{8}{ }^{(2-)}$. The maps indicate total $\mathrm{p}$ and $\mathrm{s}$ contributions for inducing current densities. As expected, the currents from the $\mathrm{p}$ electrons are strongly dia-tropic in benzene and strongly para-tropic in COT. The currents are overmatched by HOMO contributions in both cases. Angular-momentum analysis exhibits how the symmetry rules account for these aspects. At each consecutive energy level, the quantum number, $1(=0,1 \ldots, \mathrm{N} / 2)$, increases by one. In a ring with $\mathrm{N}=4 \mathrm{n}+2$ electrons, the HOMO and LUMO correspond to $\mathrm{n}=\alpha$ and $\mathrm{n}=\alpha+1$, respectively. Total densities of states of these molecules and ions are plotted (supplementary), as it can be seen the energies for all systems are distributed between -0.8 up to 0.2 a.u.
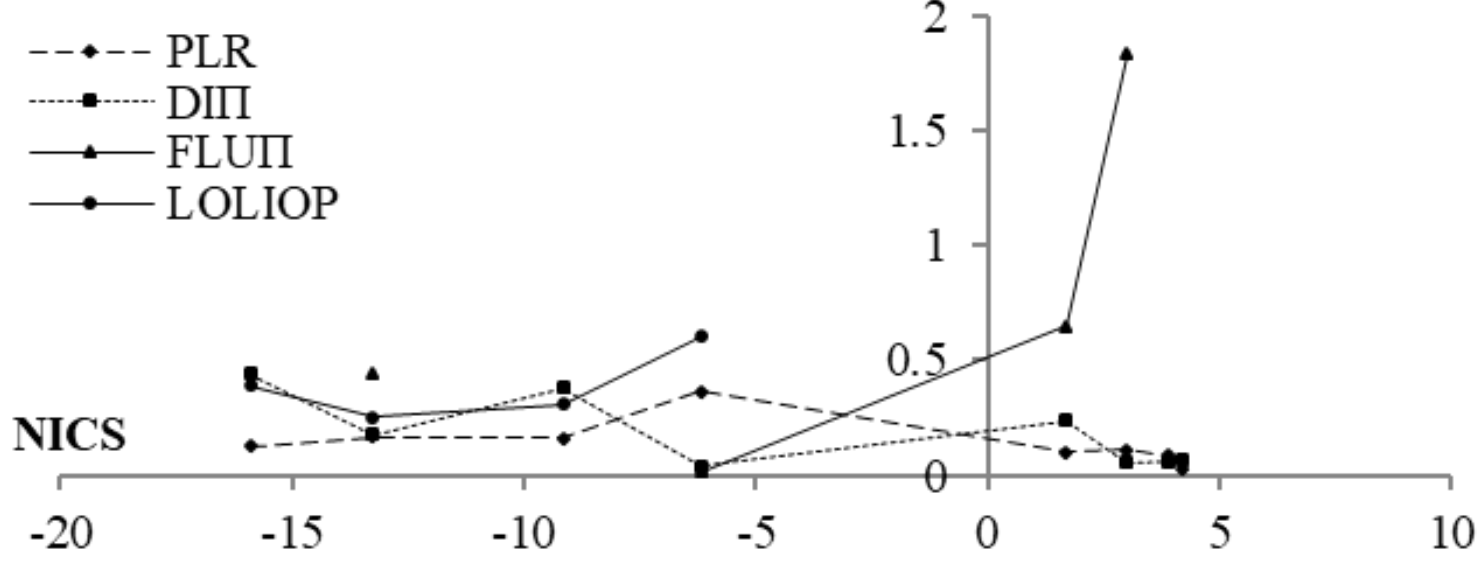

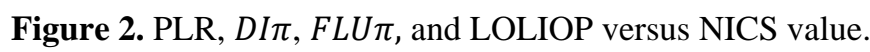




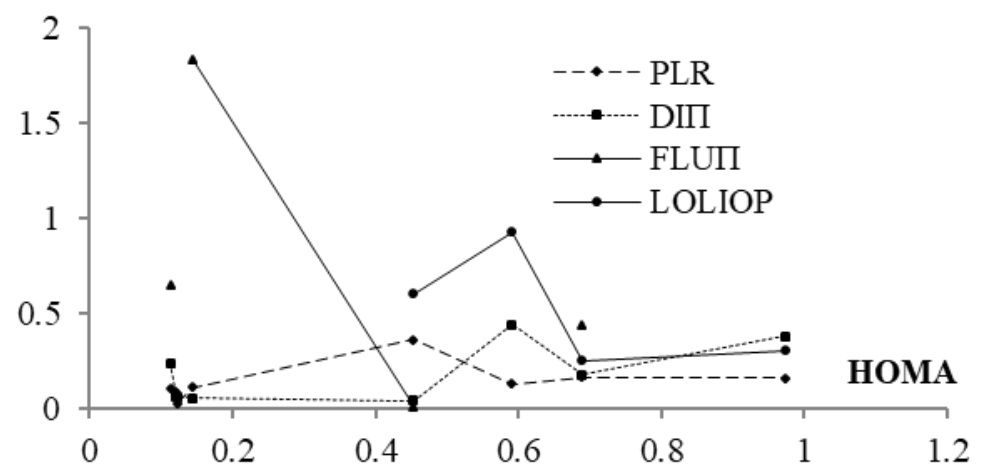

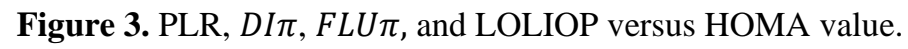

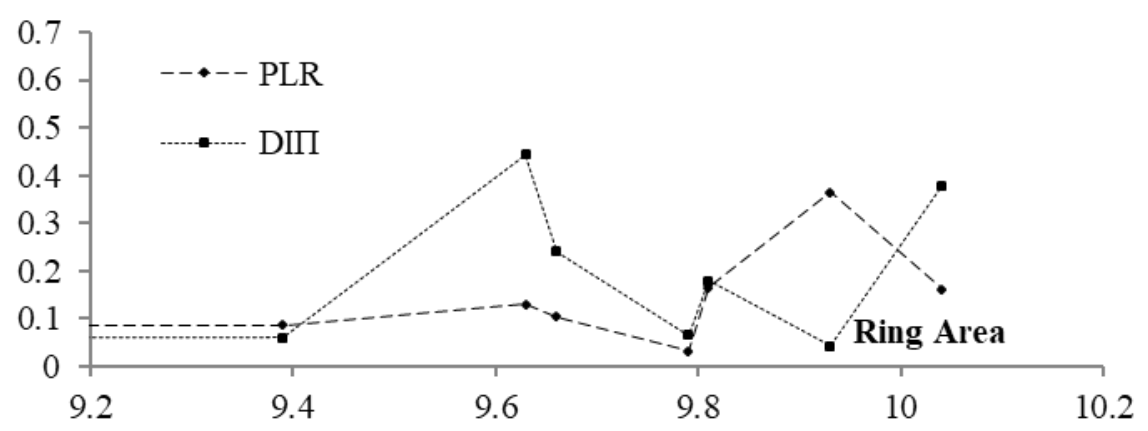

Figure 4. PLR, $D I \pi$, versus ring area value.

Table 6. Various calculations of charges and bond order for $\mathrm{B}_{4} \mathrm{~N}_{4} \mathrm{H}_{8}{ }^{0}, \mathrm{~B}_{2} \mathrm{~N}_{2} \mathrm{C}_{4} \mathrm{H}_{8}{ }^{0}$ and $\mathrm{B}_{4} \mathrm{~N}_{4} \mathrm{H}_{8}{ }^{2-}$.

\begin{tabular}{|c|c|c|c|c|c|}
\hline \multicolumn{2}{|l|}{ Molecule } & $\begin{array}{l}\text { Mayer's } \\
\text { valance }\end{array}$ & $\begin{array}{l}\text { Wiberg's bond } \\
\text { order }\end{array}$ & $\begin{array}{l}\text { Mullikan's bond } \\
\text { order }\end{array}$ & $\begin{array}{l}\text { Fuzzy's bond } \\
\text { order }\end{array}$ \\
\hline \multirow{8}{*}{$\mathrm{B}_{4} \mathrm{~N}_{4} \mathrm{H}_{8}{ }^{0}$} & $\mathrm{~N} 1, \mathrm{H} 9$ & $3.65,0.98$ & N1-B2:1.34 & N1-B2:1.06 & N1-B2:1.28 \\
\hline & B2, H10 & $3.85,0.92$ & N1-B2:1.34 & N1-B2:1.06 & N1-B2:1.28 \\
\hline & B3, H11 & $3.85,0.92$ & B2-N4:1.34 & B2-N4:1.06 & B2-N4:1.28 \\
\hline & $\mathrm{N} 4, \mathrm{H} 12$ & $3.65,0.98$ & B3-N6:1.34 & B3-N6:1.06 & B3-N6:1.28 \\
\hline & B5, H13 & $3.85,0.92$ & N4-B5:1.34 & N4-B5:1.06 & N4-B5:1.28 \\
\hline & N6, H14 & $3.65,0.98$ & B5-N7:1.34 & B5-N7:1.06 & B5-N7:1.28 \\
\hline & N7, H15 & $3.65,0.98$ & N6-B8:1.34 & N6-B8:1.06 & N6-B8:1.28 \\
\hline & B8, H16 & $3.85,0.92$ & N7-B8:1.34 & N7-B8:1.06 & N7-B8:1.28 \\
\hline \multirow{8}{*}{$\mathrm{B}_{2} \mathrm{~N}_{2} \mathrm{C}_{4} \mathrm{H}_{8}{ }^{0}$} & B1, H9 & $3.44,0.90$ & B1-N2: 1.20 & B1-N2: 0.75 & B1-N2: 1.27 \\
\hline & $\mathrm{N} 2, \mathrm{H} 10$ & $2.98,0.92$ & B1-C3: 1.37 & B1-C3: 1.23 & B1-C3: 137 \\
\hline & C3, H11 & $3.82,0.94$ & C3-C6: 1.45 & C3-C6: 0.99 & C3-C6: 1.52 \\
\hline & $\mathrm{C} 4, \mathrm{H} 12$ & $3.67,0.92$ & N2-C4: 1.24 & N2-C4: 0.56 & N2-C4: 1.39 \\
\hline & C5, H13 & $3.82,0.92$ & C5-C4: 1.46 & C5-C4: 0.99 & C5-C4: 0.99 \\
\hline & C6, H14 & $3.67,0.94$ & C5-B7: 1.37 & C5-B7: 1.23 & C5-B7: 1.52 \\
\hline & B7, H15 & $3.44,0.83$ & C6-N8: 1.24 & C6-N8: 0.56 & C6-N8: 1.38 \\
\hline & N8, H16 & $2.98,0.90$ & B7-N8: 1.20 & B7-N8: 0.75 & B7-N8: 1.27 \\
\hline \multirow{8}{*}{$\mathrm{B}_{4} \mathrm{~N}_{4} \mathrm{H}_{8}{ }^{2-}$} & B1, H9 & $3.35,0.86$ & B1-N2: 1.244 & B1-N2: 0.78 & B1-N2: 1.30 \\
\hline & $\mathrm{N} 2, \mathrm{H} 10$ & $2.98,0.90$ & B1-N3: 1.244 & B1-N3: 0.78 & B1-N3: 1.30 \\
\hline & N3, H11 & $2.98,0.90$ & N2-B4: 1.244 & N2-B4: 0.78 & N2-B4: 1.30 \\
\hline & B4, H12 & $3.35,0.86$ & B4-N5: 1.244 & B4-N5: 0.78 & B4-N5: 1.30 \\
\hline & N5, H13 & $2.98,0.90$ & N5-B7: 1.244 & N5-B7: 0.78 & N5-B7: 1.30 \\
\hline & B6, H14 & $3.35,0.86$ & B7-N8: 1.244 & B7-N8: 0.78 & B7-N8: 1.30 \\
\hline & B7, H15 & $3.35,0.86$ & N8-B6: 1.244 & N8-B6: 0.78 & N8-B6: 1.30 \\
\hline & N8, H16 & $2.98,0.90$ & B6-N3: 1.244 & B6-N3: 0.78 & B6-N3: 1.30 \\
\hline
\end{tabular}

For $\mathrm{BNC}_{6} \mathrm{H}_{8}{ }^{(0)}, \mathrm{B}_{4} \mathrm{~N}_{4} \mathrm{H}_{8}{ }^{(0)}, \mathrm{C}_{8} \mathrm{H}_{8}{ }^{(0)}, \mathrm{B}_{2} \mathrm{~N}_{2} \mathrm{C}_{4} \mathrm{H}_{8}{ }^{(0)}$ molecules, which exhibit antiaromaticity of the densities, in the ranges of energies between -0.2 up to 0.0 are Zero while for those molecules with aromaticity behavior are not this value. The LOL for all variants of $\mathrm{B}_{4} \mathrm{~N}_{4} \mathrm{H}_{8}{ }^{2-}$ and $\mathrm{C}_{8} \mathrm{H}_{8}{ }^{2-}$ bonds are plotted (supplementary), the locations of sharp peak, and also the distances between two sharp peaks in each bond are related to $(\sigma)$ or $(\pi)$ bonds. 

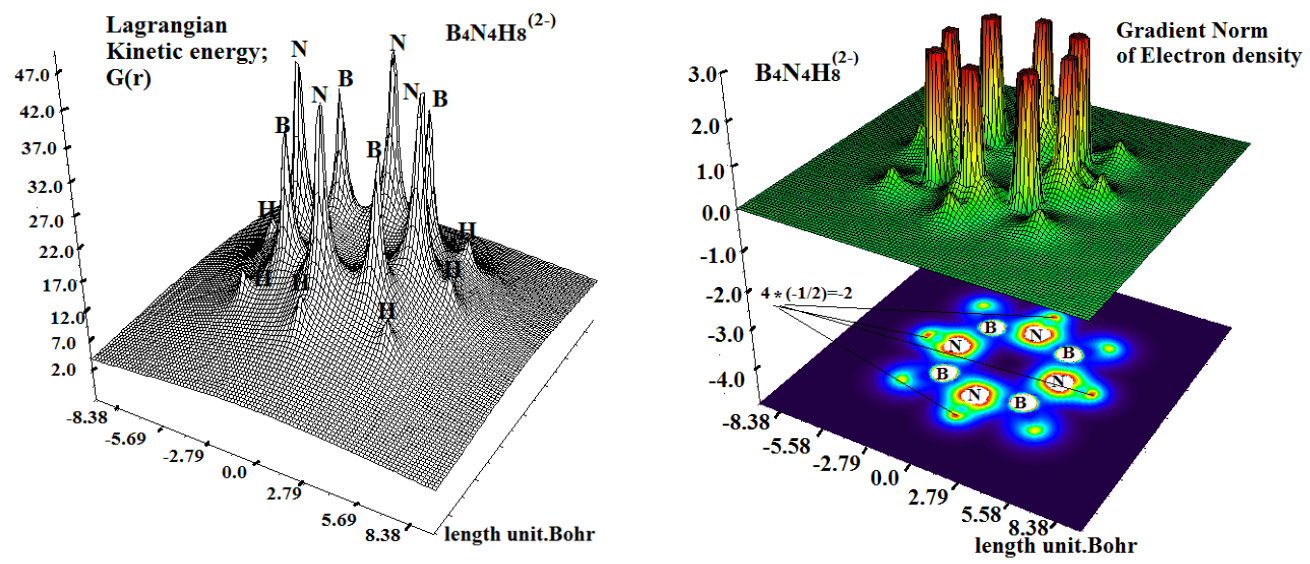

Figure 5. Shaded surface map with a projection of density of state of Lagrangian and kinetic densities of $\mathrm{B}_{4} \mathrm{~N}_{4} \mathrm{H}_{8}{ }^{2-}$.

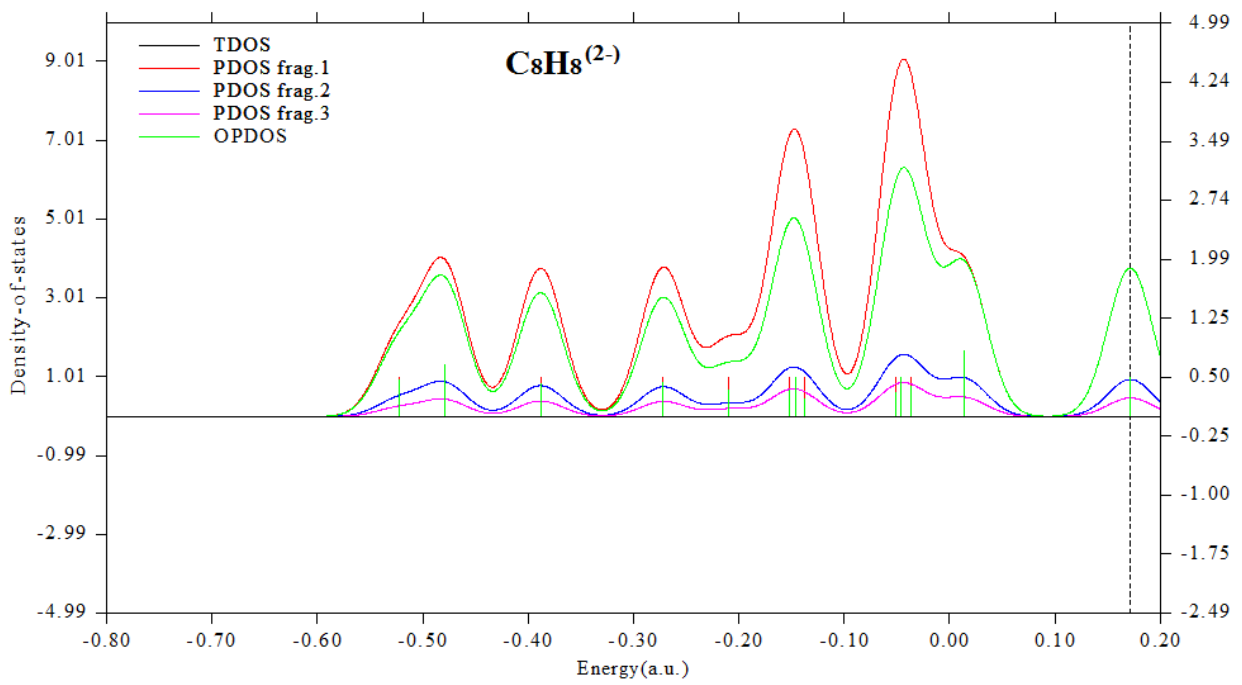

Figure 6. Total density of state (TDOS), the partial density of state (PDOS), and Overlap population density-ofstates for $\mathrm{C}_{8} \mathrm{H}_{8}{ }^{(2-)}$.
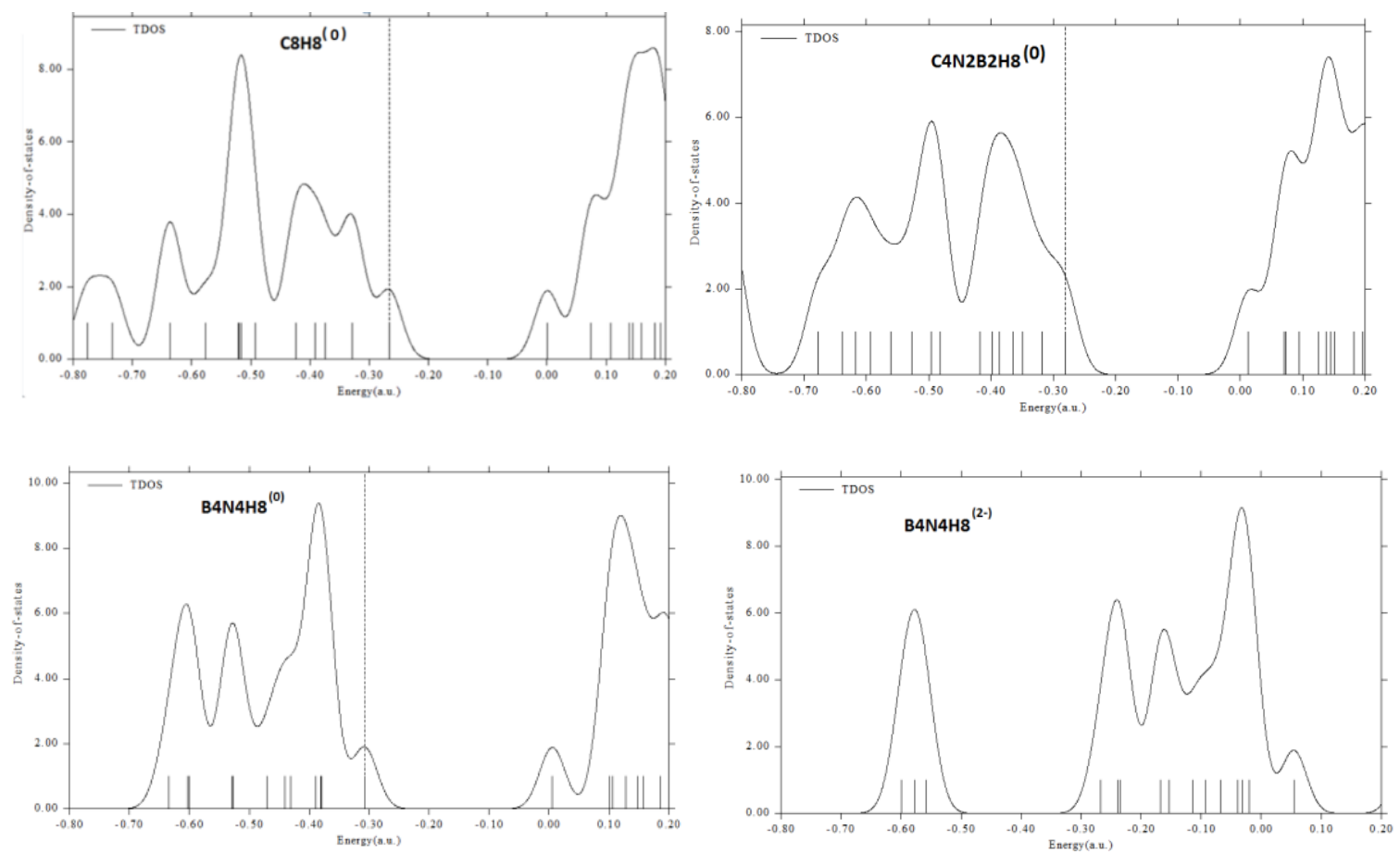

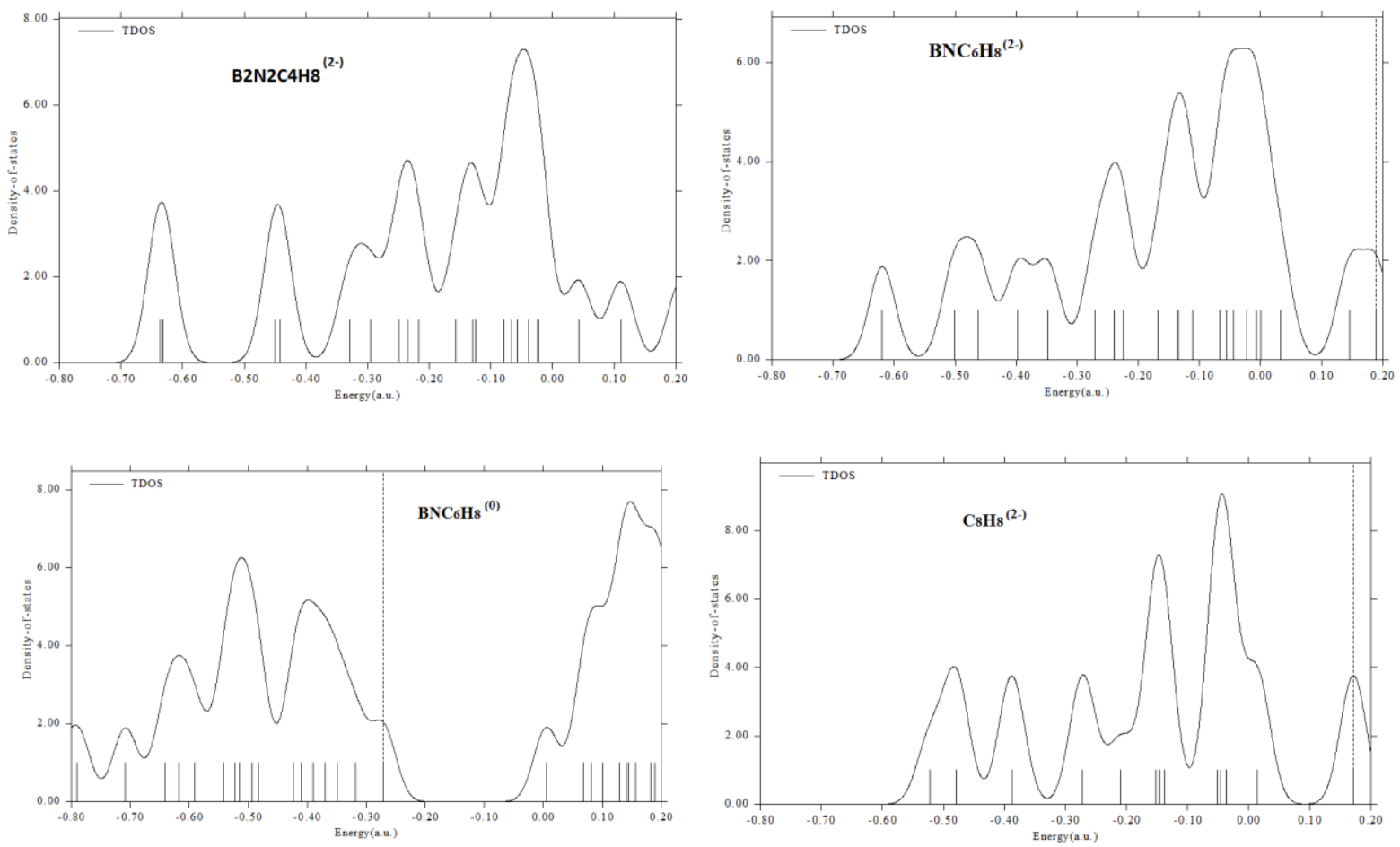

Figure 7. Total density of states of variant molecules and ions.

The calculation of charges and bond orders for several molecules is listed in Table 6 and plotted in Fig. 8. Since the bonds order is the integer number of chemical bonds, in molecules that have resonance or non-classical bonding, bond order may not be an integer. In other words, the delocalized molecular orbitals contain $\pi$ orbitals, essentially yielding half a $\pi$ together with the $\sigma$ bonds for each pair of atoms. But generally, giving a calculated bond order, which is not 1.5, depends on complex scenarios and essentially refers to bond strength relative to bonds with order 1 . As can be seen in Fig. 8, the stable electrostatic for those molecules started around the bond lengths position. Total electrostatic potential for variants of $\mathrm{BNC}_{6} \mathrm{H}_{8}{ }^{(2-)}, \mathrm{BNC}_{6} \mathrm{H}_{8}{ }^{(0)}, \mathrm{B}_{4} \mathrm{~N}_{4} \mathrm{H}_{8}{ }^{(0)}, \mathrm{B}_{2} \mathrm{~N}_{2} \mathrm{C}_{4} \mathrm{H}_{8}{ }^{2-}, \mathrm{B}_{4} \mathrm{~N}_{4} \mathrm{H}_{8}{ }^{(2-)}$ and $\mathrm{B}_{4} \mathrm{~N}_{4} \mathrm{H}_{8}{ }^{(0)}$ are shown in Fig. 8 which the sharp peaks are located in $1.166,1.127 .1 .138$ and 1.385 , respectively.
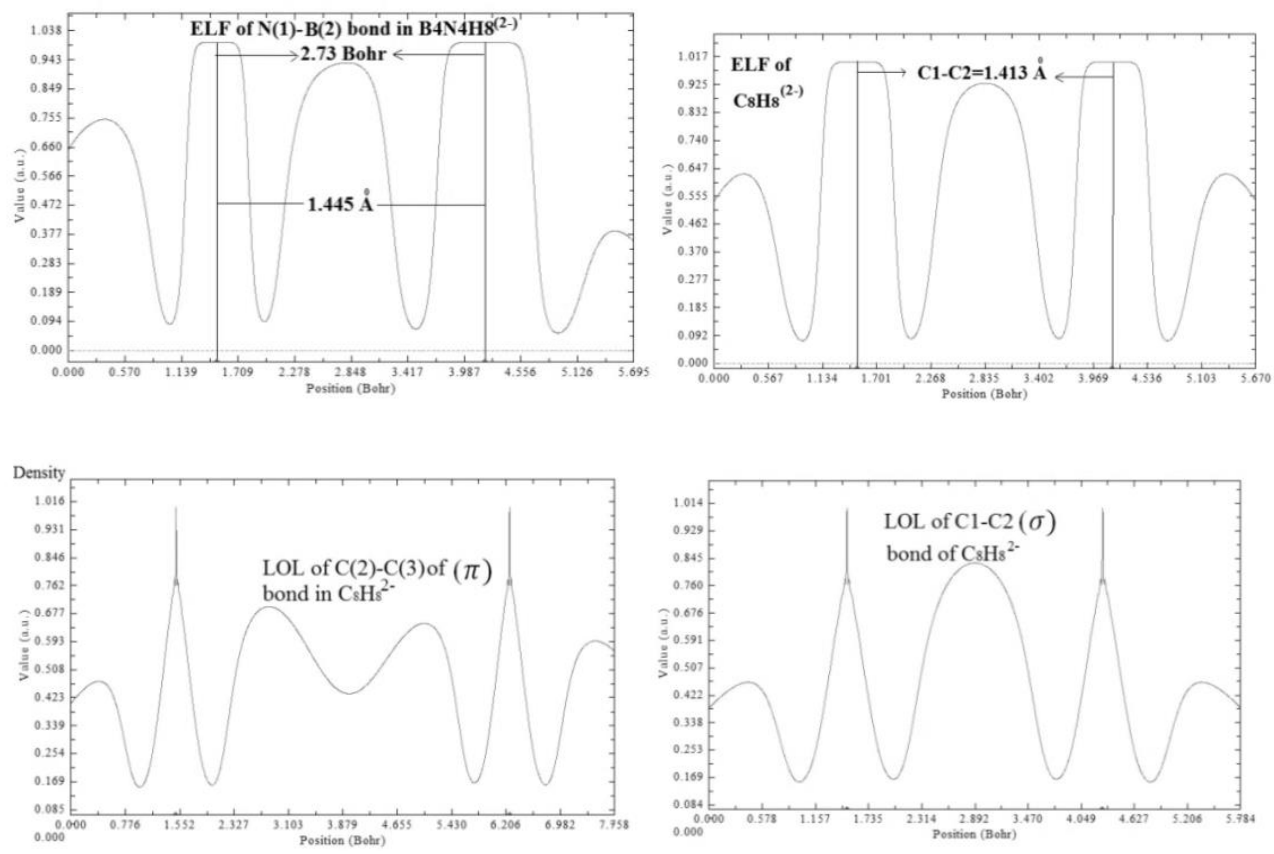

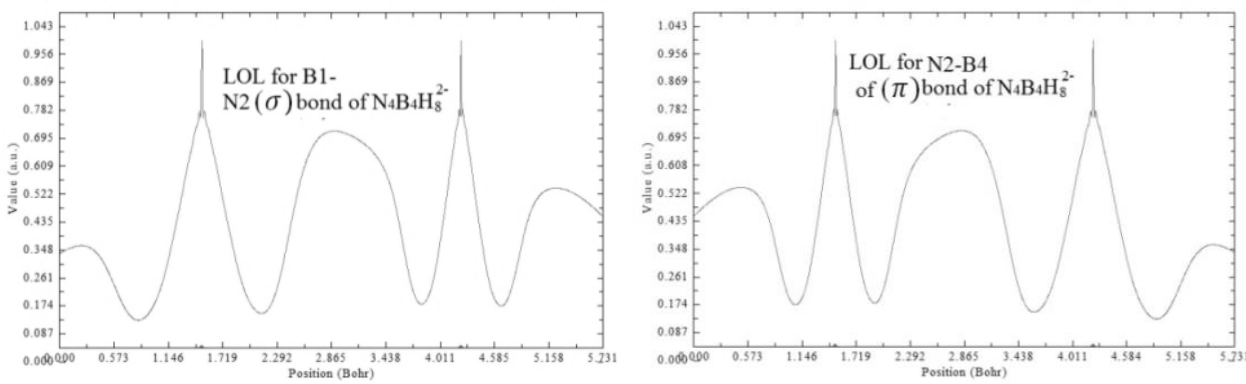

Figure 8. ELF and LOL for $\mathrm{B} 4 \mathrm{~N}_{4} \mathrm{H}_{8}{ }^{2-}$ and $\mathrm{C}_{8} \mathrm{H}_{8}{ }^{2-}$ bonds.

\section{Conclusions}

Current-density maps, ELF, and LOL from ab-initio calculations for the $\mathrm{C}_{8} \mathrm{H}_{8}{ }^{(\mathrm{n}+2)}(\mathrm{n}=-$ $4,-2,0) \& \mathrm{~B}_{\mathrm{n}} \mathrm{N}_{\mathrm{n}} \mathrm{C}_{(8-2 \mathrm{n})} \mathrm{H}_{8},(\mathrm{n}=2,4)$ are investigated as a novel method for understanding the aromaticity and anti-aromaticity in boron-nitride compounds by this work. For each molecule, the maps indicate total $p$ and s contributions for inducing current density. As expected, the currents arising from the $\mathrm{p}$ electrons are, respectively, strongly diatropic in benzene and strongly para-tropic in COT and $\mathrm{B}_{4} \mathrm{~N}_{4} \mathrm{H}_{8}{ }^{2-}$. An angular-momentum analysis shows how the symmetry rules will be for these aspects. The currents are dominated by HOMO contributions in both cases. The HOMO/LUMO overlapping in whole spaces indicates the sum over states, producing a strong two-electron paramagnetic ring current. Anti-aromaticity is a result of HOMO/HOMO-1 overlapping in whole spaces. An individual vision of aromaticity indexes based on NICS, HOMA, FLU, FLU $\pi$, PDI, LOL and ELF variables is not sufficient, and it is necessary to consider a few of these variables for any prediction and discussion due to this reality that aromaticity is not like a digital number [ 1 or zero].

\section{Funding}

This research received no external funding.

\section{Acknowledgments}

Thanks to the Central Tehran Branch, Islamic Azad University for supporting computational software and all necessary equipment.

\section{Conflicts of Interest}

The authors declare no conflict of interest.

\section{References}

1. Scherer, W.; Sirsch, P.; Grosche, M.; Spiegler, M.; Mason, S. A.; Gardiner, M. G. Agostic Deformations Based on Electron Delocalization in the Alkyllithium-Complex [(2- Me3Si) 2CLiC5H4N)2. Chem. Commun. 2001, 2072, https://doi.org/10.1039/b105452j.

2. Scherer, W.; Sirsch, P.; Shorokhov, D.; Tafipolsky, M.; McGrady, G. S.; Gullo, E. Valence Charge Concentrations, Electron Delocalization and $\beta$-Agostic Bonding in $\mathrm{d}^{0}$ Metal Alkyl Complexes Chem. Eur. J. 2003, 9, https://doi.org/10.1002/chem.200304909.

3. Poater, J.; Duran, M.; Sola, M.; Silvi, B. Theoretical Evaluation of Electron Delocalization in Aromatic Molecules by Means of Atoms in Molecules (AIM) and Electron Localization Function (ELF) Topological Approaches. Chem. Rev. 2005, 105, 3911-3947, https://doi.org/10.1021/cr030085x.

4. Poater, J.; Fradera, X.; Duran, M.; Sola, M. The Delocalization Index as an Electronic Aromaticity Criterion: Application to a Series of Planar Polycyclic Aromatic Hydrocarbons. Chem. Eur. J. 2003, 9, https://doi.org/10.1002/chem.200390041. 
5. $\quad$ Bader, R.F.W.; Streitwieser, A.; Neuhaus, A.; Laidig, K.E.; Speers, P. The Quantum Theory of Atoms in Molecules: From Solid State. J. Am. Chem. Soc. 1996, 118.

6. Bader, R.F.W. Atoms in Molecule: A quantum Theory. Oxford Univ. press, Oxford, 1990.

7. Poater, J.; Fradera, X.; Duran, M.; Sola, M. Fullerenes: The Exciting World of Nanocages and Nanotubes. Kamat, P.V., Kadish, K.M., Guldi, D. Eds.; The Electrochemical Society: Pennington, NJ, 2002; pp. 12.

8. Becke, A.D.; Edgecombe, K.E.; A simple measure of electron localization in atomic and molecular systems. J. Chem. Phys.1990, 92, https://doi.org/10.1063/1.458517.

9. Savin, A.; Flad, H.J.; Flad, J.; Preuss, H.; von Schnering, H.G. On the Bonding in Carbosilanes, Angew. Chem. Int. Ed.Engl.1992, 32, 187.

10. Becke, A.D. Chemical content of the kinetic energy density. J. Mol. Struct. (Theochem) 2000, 527, 51-56, https://doi.org/10.1016/S0166-1280(00)00477-2.

11. Willstätter, R.; Waser, E. Über Cyclo-octatetraen [On cyclooctatetraene]. Ber. Dtsch. Chem. Ges 1911, 44, 3423-3445.

12. Schlichting, O; Klager, K.; Toepel, T. Cyclisierende Polymerisation von Acetylen. I. Über Cyclooctatetraen [Ring-forming polymerization of acetylene. I. Cyclooctatetraene]. Liebigs Ann. Chem. 1948, 560,1-92.

13. Fernández, W. J. I.; Mo, Y.; Schleyer, P. V. R. Why Cyclooctatetraene Is Highly Stabilized: the Importance of "Two-Way" (Double) Hyperconjugation. J. Chem.Theory Comput. 2012, 8, 1280-1287, https://doi.org/10.1021/ct3000553.

14. Naor, R.; Luz, Z. Bond Shift Kinetics in Cyclo -Octatetraene by Dynamic NMR in Liquid Crystalline Solvents. The Journal of Chemical Physics 1982, 76, 5662-5664.

15. Andrés, J.L.; Castaño, O.; Morreale, A.; Palmeiro, R.; Gomperts, R. Potential Energy Surface of Cyclooctatetraene. The Journal of Chemical Physics. 1998, 108, 203-207.

16. Nishinaga, T.; Ohmae, T.; Iyoda, M. Recent Studies on the Aromaticity and Antiaromaticity of Planar Cyclooctatetraene. Symmetry 2010, 2, 76-97, https://doi.org/10.3390/sym2010076.

17. Gellini,C.; Salvi, P.R. Structures of Annulenes and Model Annulene Systems in the Ground and Lowest Excited States. Symmetry 2010, 2, 1846-1924, https://doi.org/10.3390/sym2041846.

18. Wenthold, P.G. .; Hrovat, D.A.; Borden, W.T. Transition-state spectroscopy of yclooctatetraene. Science 1996, 272, 1456-1459, https://doi.org/10.1126/science.272.5267.1456.

19. Schild, A.; Paulus, B. Multireference calculations for ring inversion and double bond shifting in cyclooctatetraene. J Comput Chem 2013, 34, 1393-1397, https://doi.org/10.1002/jcc.23273.

20. Hrovat, D.A.; Borden, W.T. CASSCF calculations find that D8h geometry is the transition state for double bond shifting in cyclooctatetraene. $J$ Am Chem Soc 1992, 114, 5879-5881, https://doi.org/10.1021/ja00040a071.

21. Stevenson, C.D.; Brown, E.C.; Hrovat, D.A.; Borden, W.T. Isotope effects on the ring inversion of cyclooctatetraene. J Am Chem Soc. 1998, 120, 8864-8867, https://doi.org/10.1021/ja981496b.

22. Schild, A.; Paulus, B.J. Multireference Calculations for Ring Inversion and Double Bond Shifting in Cyclooctatetraene. J. Comput. Chem. 2013, 34, 1393-1397, https://doi.org/10.1002/jcc.23273.

23. Yoshida, T.; Tokizaki, C.; Takayanagi, T. Theoretical Analysis of the Transition-State Spectrum of the Cyclooctatetraene Unimolecular Reaction: Three Degree-of Freedom Model Calculations. Chem. Phys. Lett. 2015, 634, 134-139, https://doi.org/10.1016/j.cplett.2015.06.018.

24. Steiner, E.; Fowler, P.W. Patterns of Ring Currents in Conjugated Molecules: A Few-Electron Model Based on Orbital Contributions. J. Phys. Chem. A 2001, 105, 9553-9562, https://doi.org/10.1021/jp011955m.

25. Steiner, E.; Fowler, P.W.; Havenith, R.W.A. Current Densities of Localized and Delocalized Electrons in Molecules. J. Phys. Chem. A 2002, 106, 7048-7056, https://doi.org/10.1021/jp020819u.

26. London, F. Théorie quantique des courants interatomiques dans les combinaisons aromatiques. J. Phys. Radium 1937, 8, 397-409.

27. Pauling, L. The Diamagnetic Anisotropy of Aromatic Molecules. J. Chem. Phys. 1936, 4, 673-677, https://doi.org/10.1063/1.1749766.

28. Pople, J.A. Proton magnetic resonance of hydrocarbons. J. Chem. Phys. 1956, 24, https://doi.org/10.1063/1.1742701.

29. Schleyer, P.V.R.; Maerker, C.; Dransfeld, A.; Jiao, H.; Eikema Hommes, N.J.R. Nucleus-Independent Chemical Shifts: A Simple and Efficient Aromaticity Probe. J. Am. Chem. Soc. 1996, 118, 6317-6318, https://doi.org/10.1021/ja960582d.

30. Soncini, A.; Fowler, P.W.; Jenneskens, L.W. Ring currents in large [4n+2]-annulenes. Phys. Chem.Chem. Phys. 2004, 6, 277-284, https://doi.org/10.1039/B311487B.

31. Anet, F.A.L.; O’Leary, D.J. The shielding tensor. Part II. Concepts Magn. Reson. 1992, 4, https://doi.org/10.1002/cmr.1820040103.

32. Haeberlen, U. Advances in Magnetic Resonance. Academic Press, New York. 1976.

33. Mehring, M. Principles of High Resolution NMR in Solids. 2nd.ed, Springer Verlag, Berlin,1983

34. Diehl, P.; Fluck, E.; Kosfeld, R. NMR Basic Principles and Progress. Eds.; Springer Verlag, Berlin, Volume $15,1978$. 
35. Harris, R.K.; Becker, E.D.; Cabral de Menezes, S.M.; Granger, P.; Hoffman, R.E.; Zilm, K.W. Further conventions for NMR shielding and chemical shifts (IUPAC Recommendations 2008), Ann. Magn. Reson. 2008, 33, 41-56.

36. Herzfeld, J.; Berger, A.E. Sideband intensities in NMR spectra of samples spinning at the magic angle. J. Chem. Phys. 1980, 73, https://doi.org/10.1063/1.440136.

37. Kohn, W.; Sham, L.J. Self-Consistent Equations Including Exchange and Correlation Effects. Phys. Rev A 1965, 140, 1133-1138, https://doi.org/10.1103/PhysRev.140.A1133.

38. Perdew, J.P.; Burke, K.; Ernzerhof, M. Generalized Gradient Approximation Made Simple. Phys. Rev. Lett. 1996, 77, 3865-3868, https://doi.org/10.1103/physrevlett.77.3865.

39. Lu, T.; Chen, F. Quantitative analysis of molecular surface based on improved Marching Tetrahedra algorithm. J. Mol. Graph. Model 2012, 38, 314-323, https://doi.org/10.1016/j.jmgm.2012.07.004.

40. Lu, T.; Chen, F. A Multifunctional Wavefunction Analyzer. J. Comp. Chem. 2012, 33, 580-592, https://doi.org/10.1002/jcc.22885.

41. Besler, B.H.; Merz, K.M.; Kollman, P.A. Atomic charges derived from semi empirical methods. J.comp. Chem 1990, 11, 431-439, https://doi.org/10.1002/jcc.540110404.

42. Chirlian, L.E.; Francl, M.M. Atomic charges derived from electrostatic potentials: A Detailed study. J.comp.chem 1987, 8, 894-905, https://doi.org/10.1002/jcc.540080616.

43. Martin, F.; Zipse, H. Charge distribution in the water molecule--a comparison of methods. J Comp Chem. 2005, 26, 97-105, https://doi.org/10.1002/jcc.20157.

44. Mollaamin, F.; Gharibe, S.; Monajjemi, M. Synthesis of various nano and micro ZnSe morphologies by using hydrothermal method. International Journal of Physical Sciences 2011, 6, 1496-1500.

45. Monajjemi M. Graphene/(h-BN)n/X-doped raphene as anode material in lithium ion batteries $(\mathrm{X}=\mathrm{Li}, \mathrm{Be}$, B AND N,). Macedonian Journal of Chemistry and Chemical Engineering 2017, 36, 101-118, http://dx.doi.org/10.20450/mjcce.2017.1134.

46. Monajjemi, M. Cell membrane causes the lipid bilayers to behave as variable capacitors: A resonance with self-induction of helical proteins. Biophysical Chemistry 2015, 207, 114-127, https://doi.org/10.1016/j.bpc.2015.10.003.

47. Monajjemi, M. Study of CD5+ Ions and Deuterated Variants $(\mathrm{CHxD}(5-\mathrm{x})+)$ : An Artefactual Rotation. Russian Journal of Physical Chemistry A 2018, 92, 2215-2226.

48. Monajjemi, M. Liquid-phase exfoliation (LPE) of graphite towards graphene: An ab initio study. Journal of Molecular Liquids 2017, 230, 461-472, https://doi.org/10.1016/j.molliq.2017.01.044.

49. Jalilian, H.; Monajjemi, M. Capacitor simulation including of $\mathrm{X}$-doped graphene $(\mathrm{X}=\mathrm{Li}, \mathrm{Be}, \mathrm{B})$ as two electrodes and $(\mathrm{h}-\mathrm{BN}) \mathrm{m}(\mathrm{m}=1-4)$ as the insulator. Japanese Journal of Applied Physics 2015, 54, 0851017

50. Ardalan, T.; Ardalan, P.; Monajjemi, M. Nano theoretical study of a C 16 cluster as a novel material for vitamin C carrier. Fullerenes Nanotubes and Carbon Nanostructures 2014, 22, 687-708, https://doi.org/10.1080/1536383X.2012.717561.

51. Mahdavian, L.; Monajjemi, M.; Mangkorntong, N. Sensor response to alcohol and chemical mechanism of carbon nanotube gas sensors. Fullerenes Nanotubes and Carbon Nanostructures 2009, 17, 484-495, https://doi.org/10.1080/15363830903130044.

52. Monajjemi, M.; Najafpour, J. Charge density discrepancy between NBO and QTAIM in single-wall armchair carbon nanotubes. Fullerenes Nanotubes and Carbon Nano structures 2014, 22, 575-594, https://doi.org/10.1080/1536383X.2012.702161.

53. Monajjemi, M.; Hosseini, M.S. Non bonded interaction of B16 N16 nano ring with copper cations in point of crystal fields. Journal of Computational and Theoretical Nanoscience 2013, 10, 2473- 2477

54. Monajjemi, M.; Mahdavian, L.; Mollaamin, F. Characterization of nanocrystalline silicon germanium film and nanotube in adsorption gas by Monte Carlo and Langevin dynamic simulation. Bulletin of the Chemical Society of Ethiopia 2008, 22, 277-286, https://doi.org/10.4314/bcse.v22i2.61299.

55. Lee, V.S.; Nimmanpipug, P.; Mollaamin, F.; Thanasanvorakun, S.; Monajjemi, M. Investigation of single wall carbon nanotubes electrical properties and normal mode analysis: Dielectric effects. Russian Journal of Physical Chemistry A 2009, 83, 2288-2296, https://doi.org/10.1134/S0036024409130184.

56. Mollaamin, F.; Najafpour, J.; Ghadami, S.; Akrami, M.S.; Monajjemi, M. The electromagnetic feature of B $\mathrm{N} \mathrm{H}(\mathrm{x}=0,4,8,12,16$, and 20) nano rings:Quantum theory of atoms in molecules/NMR approach. Journal of Computational and Theoretical Nanoscience 2014, 11, 1290-1298.

57. Monajjemi, M.; Mahdavian, L.; Mollaamin, F.; Honarparvar, B. Thermodynamic investigation of enolketo tautomerism for alcohol sensors based on carbon nanotubes as chemical sensors. Fullerenes Nanotubes and Carbon Nanostructures 2010, 18, 45-55, https://doi.org/10.1080/15363830903291564.

58. Monajjemi, M.; Ghiasi, R.; Seyed, S.M.A. Metal-stabilized rare tautomers: N4 metalated cytosine (M = Li , $\mathrm{Na}, \mathrm{K}, \mathrm{Rb}$ and $\mathrm{Cs}$ ), theoretical views. Applied Organometallic Chemistry 2003, 17, 635-640, https://doi.org/10.1002/aoc.469.

59. Ilkhani, A.R.; Monajjemi, M. The pseudo Jahn-Teller effect of puckering in pentatomic unsaturated rings C $\mathrm{AE}, \mathrm{A}=\mathrm{N}, \mathrm{P}, \mathrm{As}, \mathrm{E}=\mathrm{H}, \mathrm{F}, \mathrm{Cl}$.Computational and Theoretical Chemistry 2015, 1074, 19-25, http://dx.doi.org/10.1016\%2Fj.comptc.2015.10.006. 
60. Monajjemi, $\mathrm{M}$. Non-covalent attraction of $\mathrm{B} \mathrm{N}$ and repulsion of $\mathrm{B} \mathrm{N}$ in the $\mathrm{B} \mathrm{N}$ ring: a quantum rotatory due to an external field. Theoretical Chemistry Accounts 2015, 134, 1-22, https://doi.org/10.1007/s00214-0151668-9.

61. Monajjemi, M.; Naderi, F.; Mollaamin, F.; Khaleghian, M. Drug design outlook by calculation of second virial coefficient as a nano study. Journal of the Mexican Chemical Society 2012, 56, 207-211, https://doi.org/10.29356/jmcs.v56i2.323.

62. Monajjemi, M.; Bagheri, S.; Moosavi, M.S. Symmetry breaking of B2N(-,0,+): An aspect of the electric potential and atomic charges. Molecules 2015, 20, 21636-21657, https://doi.org/10.3390/molecules201219769.

63. Monajjemi, M.; Mohammadian, N.T. S-NICS: An aromaticity criterion for nano molecules. Journal of Computational and Theoretical Nanoscience 2015, 12, 4895-4914, https://doi.org/10.1166/jctn.2015.4458.

64. Monajjemi, M.; Ketabi, S.; Hashemian, Z.M.; Amiri, A. Simulation of DNA bases in water: Comparison of the Monte Carlo algorithm with molecular mechanics force fields. Biochemistry (Moscow) 2006, 71, 1-8, https://doi.org/10.1134/s0006297906130013.

65. Monajjemi, M.; Lee, V.S.; Khaleghian, M.; Honarparvar, B.; Mollaamin, F. Theoretical Description of Electromagnetic Nonbonded Interactions of Radical, Cationic, and Anionic NH2BHNBHNH2 Inside of the B18N18 Nanoring. J. Phys. Chem C 2010, 114, 15315-15330, https://doi.org/10.1021/jp104274z.

66. Monajjemi, M.; Boggs, J.E. A New Generation of BnNn Rings as a Supplement to Boron Nitride Tubes and Cages. J. Phys. Chem. A 2013, 117, 1670-1684, http://dx.doi.org/10.1021/jp312073q.

67. Monajjemi, M. Non bonded interaction between BnNn (stator) and BN B (rotor) systems: A quantum rotation in IR region. Chemical Physics 2013, 425, 29-45, https://doi.org/10.1016/j.chemphys.2013.07.014.

68. Monajjemi, M.; Robert, W.J.; Boggs, J.E. NMR contour maps as a new parameter of carboxyl's OH groups in amino acids recognition: A reason of tRNA-amino acid conjugation. Chemical Physics 2014, 433, 1-11, https://doi.org/10.1016/j.chemphys.2014.01.017.

69. Monajjemi, M. Quantum investigation of non-bonded interaction between the B15N15 ring and BH2NBH2 (radical, cation, and anion) systems: a nano molecularmotor. Struct Chem 2012, 23, 551-580, http://dx.doi.org/10.1007/s11224-011-9895-8.

70. Monajjemi, M. Metal-doped graphene layers composed with boron nitride-graphene as an insulator: a nanocapacitor. Journal of Molecular Modeling 2014, 20, 2507, https://doi.org/10.1007/s00894-014-2507-y.

71. Mollaamin, F.; Monajjemi, M.; Mehrzad, J. Molecular Modeling Investigation of an Anti-cancer Agent Joint to SWCNT Using Theoretical Methods. Fullerenes, Nanotubes and Carbon Nanostructures 2014, 22, 738751, https://doi.org/10.1080/1536383X.2012.731582.

72. Monajjemi, M.; Ketabi, S.; Amiri, A. Monte Carlo simulation study of melittin: protein folding and temperature ependence. Russian journal of physical chemistry 2006, 80, S55-S62, https://doi.org/10.1134/S0036024406130103.

73. Monajjemi, M.; Heshmata, M.; Haeria, H.H. QM/MM model study on properties and structure of some antibiotics in gas phase: Comparison of energy and NMR chemical shift. Biochemistry (Moscow) 2006, 71, S113-S122, https://doi.org/10.1134/S0006297906130190.

74. Monajjemi, M.; Afsharnezhad, S.; Jaafari, M.R.; Abdolahi, T.; Nikosade, A.; Monajemi, H. NMR shielding and a thermodynamic study of the effect of environmental exposure to petrochemical solvent on DPPC, an important component of lung surfactant. Russian Journal of Physical Chemistry A 2007, 81, 1956-1963, https://doi.org/10.1134/S0036024407120096.

75. Mollaamin, F.; Noei, M.; Monajjemi, M.; Rasoolzadeh, R. Nano theoretical studies of fMET-tRNA structuren in protein synthesis of prokaryotes and its comparison with the structure of fALA-tRNA. African journal of microbiology research 2011, 5, 2667-2674, https://doi.org/10.5897/AJMR11.310.

76. Monajjemi, M.; Heshmat, M.; Haeri, H.H.; Kaveh, F. Theoretical study of vitamin properties from combined QM-MM methods: Comparison of chemical shifts and energy. Russian Journal of Physical Chemistry 2006, 80, 1061-1068, https://doi.org/10.1134/S0036024406070119.

77. Monajjemi, M.; Chahkandi, B. Theoretical investigation of hydrogen bonding in Watson-Crick, Hoogestein and their reversed and other models: comparison and analysis for configurations of adenine-thymine base pairs in 9 models. Journal of Molecular Structure: Theochem 2005, 714, 43-60, https://doi.org/10.1016/j.theochem.2004.09.048.

78. Monajjemi, M.; Honarparvar, B.; Haeri, H.H.; Heshmat, M. An ab initio quantum chemical investigation of solvent-induced effect on 14N-NQR parameters of alanine, glycine, valine, and serine using a polarizable continuum model. Russian Journal of Physical Chemistry 2006, 80, S40-S44, https://doi.org/10.1134/S0036024406130073.

79. Monajjemi, M.; Seyed Hosseini, M. Non Bonded Interaction of B16N16 Nano Ring with Copper Cations in Point of Crystal Fields. Journal of Computational and Theoretical Nanoscience 2013, 10, 2473-2477, https://doi.org/10.1166/jctn.2013.3233.

80. Monajjemi, M.; Farahani, N.; Mollaamin, F. Thermodynamic study of solvent effects on nanostructures: phosphatidylserine and phosphatidylinositol membranes. Physics and Chemistry of Liquids 2012, 50, 161172, https://doi.org/10.1080/00319104.2010.527842. 
81. Monajjemi, M.; Ahmadianarog, M. Carbon Nanotube as a Deliver for Sulforaphane in Broccoli Vegetable in Point of Nuclear Magnetic Resonance and Natural Bond Orbital Specifications. Journal of Computational and Theoretical Nanoscience 2014, 11, 1465-1471, https://doi.org/10.1166/jctn.2014.3519.

82. Monajjemi, M.; Ghiasi, R.; Ketabi, S.; Passdar, H.; Mollaamin, F. A Theoretical Study of Metal-Stabilised Rare Tautomers Stability: N4 Metalated Cytosine (M=Be2+, Mg2+, Ca2+, Sr2+ and Ba2+) in Gas Phase and Different. Journal of Chemical Research 2004, 1, 11-18, https://doi.org/10.3184/030823404323000648.

83. Monajjemi, M.; Baei, M.T.; Mollaamin, F. Quantum mechanic study of hydrogen chemisorptions on nanocluster vanadium surface. Russian Journal of Inorganic Chemistry 2008, 53, 1430-1437, https://doi.org/10.1134/S0036023608090143.

84. Mollaamin, F.; Baei, M.T.; Monajjemi, M.; Zhiani, R.; Honarparvar, B. A DFT study of hydrogen chemisorption on V (100) surfaces. Russian Journal of Physical Chemistry A, Focus on Chemistry 2008, 82, 2354-2361, https://doi.org/10.1134/S0036024408130323.

85. Monajjemi, M.; Honarparvar, B.; Nasseri, S.M.; Khaleghian, M. NQR and NMR study of hydrogen bonding interactions in anhydrous and monohydrated guanine cluster model: A computational study. Journal of Structural Chemistry 2009, 50, 67-77, https://doi.org/10.1007/s10947-009-0009-z.

86. Monajjemi, M.; Aghaie, H.; Naderi, F. Thermodynamic study of interaction of TSPP, CoTsPc, and FeTsPc with calf thymus DNA. Biochemistry (Moscow) 2007, 72, 652-657, https://doi.org/10.1134/S0006297907060089.

87. Monajjemi, M.; Heshmat, M.; Aghaei, H.; Ahmadi, R.; Zare, K. Solvent effect on 14N NMR shielding of glycine, serine, leucine, and threonine: Comparison between chemical shifts and energy versus dielectric constant. Bulletin of the Chemical Society of Ethiopia 2007, 21, 111-116, https://doi.org/10.4314/bcse.v21i1.61387.

88. Monajjemi, M.; Rajaeian, E.; Mollaamin, F.; Naderi, F.; Saki, S. Investigation of NMR shielding tensors in 1,3 dipolar cycloadditions: solvents dielectric effect. Physics and Chemistry of Liquids 2008, 46, 299-306, https://doi.org/10.1080/00319100601124369.

89. Mollaamin, F.; Varmaghani, Z.; Monajjemi, M. Dielectric effect on thermodynamic properties in vinblastine by DFT/Onsager modelling. Physics and Chemistry of Liquids 2011, 49, 318-336, https://doi.org/10.1080/00319100903456121.

90. Monajjemi, M.; Honaparvar, B.; Khalili Hadad, B.; Ilkhani, A.; Mollaamin, F. Thermo-Chemical Investigation and NBO Analysis of Some anxileotic as Nano-Drugs. African journal of pharmacy and pharmacology 2010, 4, 521-529.

91. Monajjemi, M.; Khaleghian, M.; Mollaamin, F. Theoretical study of the intermolecular potential energy and second virial coefficient in the mixtures of $\mathrm{CH} 4$ and $\mathrm{Kr}$ gases: a comparison with experimental data. Molecular Simulation 2010, 36, 865-870, https://doi.org/10.1080/08927022.2010.489557.

92. Monajjemi, M.; Khosravi, M.; Honarparvar, B.; Mollaamin, F. Substituent and solvent effects on the structural bioactivity and anticancer characteristic of catechin as a bioactive constituent of green tea. International Journal of Quantum Chemistry 2011, 111, 2771-2777, https://doi.org/10.1002/qua.22612.

93. Tahan, A.; Monajjemi, M. Solvent dielectric effect and side chain mutation on the structural stability of Burkholderia cepacia lipase active site: a quantum mechanical/molecular mechanics study. Acta Biotheor 2011, 59, 291-312, https://doi.org/10.1007/s10441-011-9137-x.

94. Monajjemi, M.; Khaleghian, M. EPR Study of Electronic Structure of [CoF6]3-and B18N18 Nano Ring Field Effects on Octahedral Complex. Journal of Cluster Science 2011, 22, 673-692, https://doi.org/10.1007/s10876-011-0414-2.

95. Monajjemi, M.; Mollaamin, F. Molecular Modeling Study of Drug-DNA Combined to Single Walled Carbon Nanotube. Journal of Cluster Science 2012, 23, 259-272, https://doi.org/10.1007/s10876-011-0426-y.

96. Mollaamin, F.; Monajjemi, M. Fractal Dimension on Carbon Nanotube-Polymer Composite Materials Using Percolation Theory. Journal of Computational and Theoretical Nanoscience 2012, 9, 597-601, https://doi.org/10.1166/jctn.2012.2067.

97. Mahdavian, L.; Monajjemi, M. Alcohol sensors based on SWNT as chemical sensors: Monte Carlo and Langevin dynamics simulation. Microelectronics Journal 2010, 41, 142-149, https://doi.org/10.1016/j.mejo.2010.01.011.

98. Monajjemi, M.; Falahati, M.; Mollaamin, F. Computational investigation on alcohol nanosensors in combination with carbon nanotube: a Monte Carlo and ab initio simulation. Ionics 2013, 19, 155-164, https://doi.org/10.1007/s11581-012-0708-X.

99. Mollaamin, F.; Monajjemi, M. DFT outlook of solvent effect on function of nano bioorganic drugs. Physics and Chemistry of Liquids 2012, 50, 596-604, https://doi.org/10.1080/00319104.2011.646444.

100. Gellini, C.; Salvi, P.R. Structures of Annulenes and Model Annulene Systems in the Ground and Lowest Excited States. Symmetry 2010, 2, 1846-1924, https://doi.org/10.3390/sym2041846.

101. Frost, A.A.; Musulin, B. A mnemonic device for molecular orbital energies. J. Chem. Physics 1953, 21, https://doi.org/10.1063/1.1698970.

102. Mollaamin, F.; Naiemi, M.; Monajjemi,M.; Vinblastine and vincristine as anticancer moleculesstopping the tubulin dimers, Letters in applied nano bio sciences, 2019, 9 , https://doi.org/ 10. 33263/LIANBS00.000000 
103. Aliakbarzadeh Roudsary, M; Zare, K ; Aghaei, H ; Monajjemi, M.; Electron Densities \& CycloVoltammetry Studies of $\mathrm{Mg}, \mathrm{Al}$ and Ca Calix-Aren Complexes, Letters in applied nano bio sciences, 2020, 9, 3, 1320-1332, https://doi.org/10.33263/LIANBS93.13201332. 